\title{
Economic Optimization of Operations for Hybrid Energy Systems under Variable Markets
}

\author{
Jun Chen and Humberto E. Garcia
}

Idaho National Laboratory, Idaho Falls, ID 83415, USA

\begin{abstract}
Hybrid energy systems (HES) have been proposed to be an important element to enable increasing penetration of clean energy. This paper proposes a methodology for operations optimization to maximize their economic value based on predicted renewable generation and market information. A multi-environment computational platform for performing such operations optimization is also developed. To compensate for prediction error, a control strategy is accordingly designed to operate a standby energy storage element (ESE) to avoid energy imbalance within HES. The proposed operations optimizer allows systematic control of energy conversion for maximal economic value. Simulation results of two specific HES configurations illustrate the proposed methodology and computational capability. Economic advantages of such operations optimizer and associated flexible operations are demonstrated by comparing the economic performance of flexible operations with that of constant operations. Sensitivity analysis with respect to market variability and prediction error are also performed.
\end{abstract}

Keywords: Hybrid energy systems, renewable, operations optimization, economic analysis, power market.

\section{Introduction}

\subsection{Background and Motivation}

Hybrid energy systems (HES) under flexible operations and variable energy generations/utilizations have been proposed to be an important element to enable higher penetration of clean energy generation, e.g., renewable and nuclear options, [1-9]. HES typically integrate multiple energy inputs (e.g., nuclear and renewable energy) and multiple energy outputs (e.g., electricity, gasoline, and fresh water) using complementary energy conversion processes. By enabling more than one option for energy utilization, HES configurations can change their electricity generation or consumption within a short time whenever requested.

Prior works have been focused on dynamic modeling and simulation of diverse unit operations, together with their integration, control, and dynamic property characterization [5-8]. These results suggest that, from a technical point of view, HES can be operated under flexible operations schedules to accommodate the variability introduced from renewable generation, modern loads (such as electric vehicles), and markets. Such flexibility allows HES to participate in several wholesale markets, including markets for electrical energy, feedstock, and alternative energy outputs. Previous technical evaluation of HES has also shown that HES meet the requirements to bid into

\footnotetext{
"Corresponding Author: Humberto E. Garcia; email: humberto.garcia@inl.gov; Tel: +1 208526 7769; Fax: +1 2085263677
}

wholesale ancillary service (AS) market [5], to support the stability of the electric grid. A high-level diagram of a general HES considered here is shown in Fig. 1, where HES take energy inputs from Controllable Energy Resources (CER) such as baseload generation (e.g., nuclear station), Variable Energy Resources (VER) such as wind farm, and Energy Storage Elements (ESE) such as electrical battery. HES typically include one or more Alternative Production Plants (APP) besides a Power Cycle (PC) for electricity generation. These APP allow the repurposing of energy (in form of thermal energy and/or electrical energy) for nonelectricity commodity production. HES interrelate with feedstock market $\mathrm{FM}_{i}$ for procurement of feedstock material $\mathrm{f}_{i}$, with power market $\mathrm{PM}$ for the sale of electricity and ancillary service, and with commodity market $\mathrm{CM}_{j}$ for the sale of commodity $\mathrm{c}_{j}$ (alternative energy output). Furthermore, each market (FM, PM and CM) in turn includes several forward and spot markets.

Hence the objective of this paper is to develop a generic methodology and computational platform for computing operations schedule among HES constituents for optimal economic performance. As shown in Fig. 2, such operations optimizer collects predicted information on VER generation and markets (denoted with dash lines), and updates the operations of the given HES through low-level controllers. Since HES participate in ancillary service market, controllers are also subject to grid system operator commands in case that reserved capacity is called upon. Note that since prediction error can cause energy imbalance within HES, an ESE is utilized to ensure energy bal- 


\section{Nomenclature}

$\alpha_{a h g} \quad$ capital cost per unit of installed capacity of AHG

$\alpha_{a p p} \quad$ capital cost per unit of installed capacity of APP

$\alpha_{\text {ese }} \quad$ capital cost per unit of installed capacity of ESE

$\alpha_{p h g} \quad$ capital cost per unit of installed capacity of PHG

$\alpha_{\text {ren }} \quad$ capital cost per unit of installed capacity of REN

$\beta_{\mathrm{CO}_{2}}$ taxation rate over $\mathrm{CO}_{2}$

$\beta_{f_{-} a h g}$ fraction between $O \& M_{f_{-} a h g}$ and $C_{a h g}$

$\beta_{f_{-} a p p}$ fraction between $O \& M_{f_{-} a p p}$ and $C_{a p p}$

$\beta_{f_{-} e s e}$ fraction between $O \& M_{f_{-} e s e}$ and $C_{\text {ese }}$

$\beta_{f_{-} p h g}$ fraction between $O \& M_{f_{-} p h g}$ and $C_{p h g}$

$\beta_{f_{-} r e n}$ fraction between $O \& M_{f_{-} r e n}$ and $C_{r e n}$

$\beta_{v_{-} a h g, n}$ price of the $n$th feedstock by AHG

$\beta_{v_{-} a p p, n}$ price of the $n$th feedstock by APP

$\gamma_{\mathrm{CO}_{2}}$ coefficient for computing GHG emission

$\pi_{a p p} \quad$ price of alternative product

$\pi_{d a, a s}$ price of ancillary service in DAM

$\pi_{d a, e} \quad$ price of electrical energy in DAM

$\pi_{r t} \quad$ price of electrical energy in RTM

$\rho_{d a, k} \quad$ depreciation and amortization rate for year $k$

$\sigma \quad$ tax rate

$\sim \quad$ prediction of corresponding variables

$B_{1}, B_{2}, B_{3}$ feasibility conditions

$C_{a h g}$ auxiliary heat generation capital cost

$C_{a p p}$ alternative production plant capital cost

$C_{c a p} \quad$ total capital cost

$C_{\text {ese }}$ energy storage system capital cost

$C_{g h g, k}$ cost for GHG emission for year $k$

$C_{O \& M, k}$ operations and maintenance cost for year $k$

$C_{p h g} \quad$ primary heat generation capital cost

$C_{r e n}$ renewable energy generation capital cost

$C A P E X_{k}$ capital expense for year $k$

$D A_{k} \quad$ depreciation and amortization for year $k$

$F C F F_{R, k}$ year- $k$ real discounted free cash flow to firm

$i \quad$ inflation rate

$M_{a p p}$ production rate of alternative product

$M_{\mathrm{Co}_{2}}$ combined $\mathrm{CO}_{2}$ emission

$M_{v_{-} a h g, n}$ consuming rate of the $n$th feedstock by AHG

$M_{v_{-} a p p, n}$ consuming rate of the $n$th feedstock by APP

$O \& M$ operations and maintenance

$O \& M_{f}$ fixed operations and maintenance cost

$O \& M_{v}$ variable operations and maintenance cost

$O \& M_{f_{-} a h g}$ fixed O\&M cost of AHG

$O \& M_{f_{-} a p p}$ fixed O\&M cost of APP

$O \& M_{f_{-} e s e}$ fixed O\&M cost of ESE

$O \& M_{f_{-} p h g}$ fixed O\&M cost of PHG

$O \& M_{f_{-} r e n}$ fixed O\&M cost of REN

$O \& M_{v_{-} a h g}$ variable $\mathrm{O} \& \mathrm{M}$ cost of $\mathrm{AHG}$

$O \& M_{v_{-} a p p}$ variable O\&M cost of APP

$P_{a p p} \quad$ power generated by PHG and consumed by APP

$P_{a p p}^{L} \quad$ minimum power consumed by APP

$P_{a p p}^{U} \quad$ maximum power consumed by APP

$p_{a s} \quad$ probability of reserved capacity to be called for
$P_{d a, a s}, P_{d a, a s}^{U}$ AS sold in DAM and its upper limit

$P_{d a, e}$ amount of electrical energy sold in DAM

$P_{d a, r t}, P_{d a, r t}^{U}$ power held for RTM and its upper limit

$P_{p h g} \quad$ power generated by $\mathrm{PHG}$

$P_{\text {ren }}$ power generated by REN

$P_{r t} \quad$ amount of electrical energy sold in RTM

$R_{k} \quad$ revenue for year $k$

$r_{R} \quad$ discount rate

$R_{a p p}$ revenue from sale of alternative product

$R_{d a, a s}$ revenue from sale of ancillary service in DAM

$R_{d a, e}$ revenue from sale of electrical energy in DAM

$R_{r t} \quad$ revenue from sale of electrical energy in RTM

$T_{p b} \quad$ payback period

$\mathcal{N}_{\text {ahg }} \quad$ installed capacity of AHG

$\mathcal{N}_{\text {app }} \quad$ installed capacity of APP

$\mathcal{N}_{\text {ese }} \quad$ installed capacity of smoothing ESE

$\mathcal{N}_{\text {ese }} \quad$ installed capacity of standby ESE

$\mathcal{N}_{p h g} \quad$ installed capacity of PHG

$\mathcal{N}_{\text {ren }}$ installed capacity of REN

AHG auxiliary heat generation

APP alternative production plants

AS ancillary service

CER controllable energy resources

CHP combined heat and power

CM commodity market

DAM, DAO day-ahead market, day-ahead optimizer

DB database

ESE energy storage systems

FM feedstock market

FMI functional mockup unit

FOM figure of merit

ForM forward market

GHG greenhouse gas

GPP gasoline production plant

HES hybrid energy systems

HES_FEL HES with flexible electrical load

HES_FTL HES with flexible thermal load

HRES hybrid renewable energy systems

IRR internal rate of return

MW, MWh megawatt and megawatt-hour

NG natural gas

NPV net present value

$\mathrm{PC}$ power cycle

PHG primary heat generation

PM power market

PV photovoltaics

REN renewable energy input

RODP reverse osmosis desalination plant

RTM, RTO real-time market, real-time optimizer

SM spot market

VER variable energy resources

WACC weighted average cost of capital 


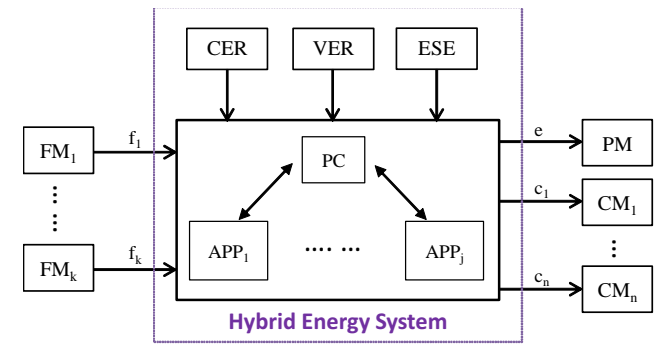

Figure 1: High-level diagram of hybrid energy systems and their interactions with various markets.

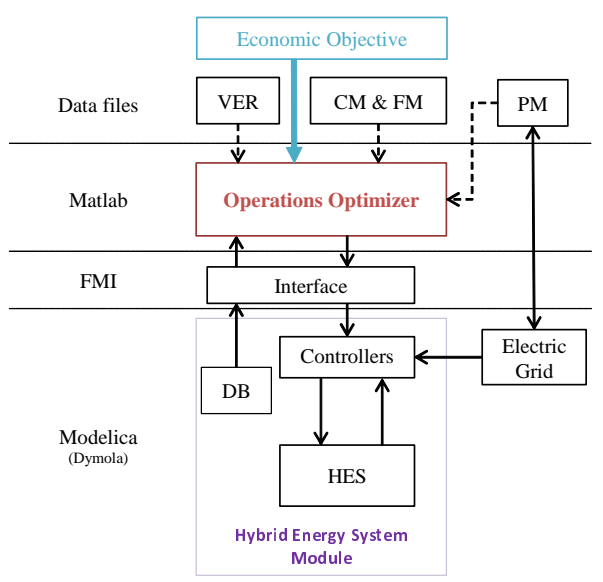

Figure 2: High-level description of the proposed operations optimizer.

ance at all time, as shown in Fig. 1.

\subsection{Proposed methodology}

An illustration of the proposed methodology for operations optimizer is shown in Fig. 3. For each delivery time $t$ (at which all the products sold in each forward market [ForM] and spot market [SM] need to be delivered), the operations optimizer considers $N$ forward markets and one spot market. The optimization starts at ForM $\mathrm{F}_{1}$ by computing the optimal strategy between selling products at For $_{1}$ and reserving energy capacity for the next market based on available information for ForM 1 , prediction of VER generation, and information about later markets. The optimization problem at ForM $\mathrm{M}_{1}$ is also constrained by condition $C_{1}$ calculated from system dynamics as well as available resources. Such optimization repeats for each ForM and then also for SM. Similarly, the optimization for SM is based on the SM prices and VER profile, and is constrained by $C_{S}$ resulted from system dynamics and available resources. At each delivery time $t$, the optimal operations schedule is computed by adding the optimal strategies resulted from each forward and spot market.

The above methodology is developed for HES interacting with power market, feedstock markets, and commodity markets, and is implemented in Matlab. The HES

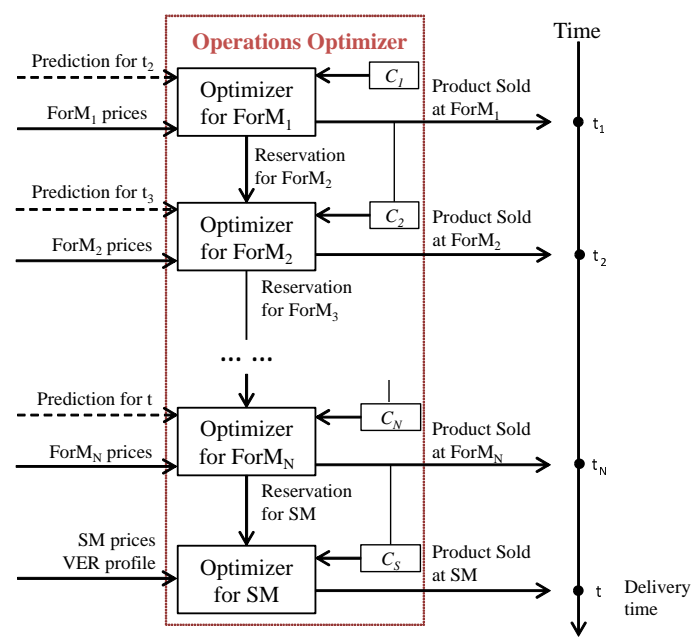

Figure 3: Schematic of the computational flow of the proposed operations optimizer.

considered are modeled and implemented in Modelica language [10] using Dymola environment [11]. The interface for interaction between the operations optimizer and HES is realized using Functional Mockup Interface (FMI) [12]. Finally, markets are modeled as time series of prices stored in database (DB).

\subsection{Technical contribution and manuscript organization}

The main contributions of this work are as follows: (1) provide a framework to economically online optimize operations of HES under variable renewable generations and market volatility; (2) evaluate the economic viability, under the proposed operations optimizer, of HES to address the variability introduced from renewable and markets; and (3) conduct dynamic analysis to investigate its sensitivity to pricing changes and prediction errors.

The rest of this paper is organized as follows. Section 2 reviews the related work in literature. Section 3 presents the topological architecture of considered HES and provides preliminaries on optimization theory. Economic figure of merits to be optimized are presented in Section 4. Section 5 formulates the operations optimization with control strategy to compensate for prediction errors. Section 6 illustrates the proposed methodology with numerical simulations. The paper is concluded in Section 6 .

\section{Literature Review}

The idea of integrating different energy resources with more than one type of energy output has been proposed in literature. For example, combined heat and power (CHP) systems [13-16] include both thermal and electric energy outputs, while hybrid renewable energy systems (HRES) [17-24] integrate different types of energy resource (e.g., wind, solar, or baseload generation) to produce electricity. The flexibility of CHP systems with thermal energy 
storage and their operational mode were studied in [14], where it was found that centralized storage unit, as a larger buffer, provides higher flexibility. Residential scale HRES without baseload generation was considered in [22], where the energy saving was calculated by life cycle cost method, and was estimated to be 195.2MWh/year for a 220 meters high building. The authors of [24] carried out a feasibility study for standalone HRES as electricity supply for remote area, and formulated net present value to assess the feasibility of different system designs. It was concluded that HRES is a promising electricity supply for Ethiopia, where current electricity coverage is less than $15 \%$. Technical and/or economic analysis for hybrid systems can be found in [25-27]. Both standalone and grid connected hybrid systems with renewable energy sources and hydrogen storage are analyzed in [25], and it is found that grid connected configuration have a higher probability of adaptation than standalone mode. The authors of [27] discovered that, when the volatility of electricity price is high enough, the use of batteries for time-of-use energy applications becomes economically attractive.

Accordingly, the optimization problems for integrated systems are also investigated in the literature for optimal system design or operational control to maximize technical and/or economic values. For example, [4] studied a design optimization problem for HES, computing the sizes of two key components for optimal production while maintaining minimal variability of process variables. References [2830] introduce a systematic approach for the design and analysis of HRES (without thermal output) using different optimization strategies (i.e., simulated annealing, response surface methodology, and OptQuest method). The proposed approach is applied to optimize the size of a photovoltaic (PV)-wind hybrid energy system with battery storage. Reference [31] suggests another optimization method for designing hybrid solar-wind systems employing battery banks. Optimum system configurations are calculated to optimize a given economic-based objective function, while meeting a specified constraint (i.e., loss of power supply probability). Similar work can also be found in [32], which optimizes the sizes of different components in a grid-independent hybrid PV-wind power systems. Design optimization is also discussed in [33], where the benefits of using bioenergy, solar thermal, and wind energy in a flexible energy system are analyzed to increase renewable penetration, decrease primary energy consumption, and assure power supply security in a particular region. The authors of [34] proposed a generalized optimization framework and applied for optimal sizing of distributed energy resources in medium or low voltage microgrids.

The literature operations optimization are reviewed as follows. Reference [13] considered the combined cooling, heating, and power systems, and their operational strategy. Instead of optimizing economic objective, the goal in [13] was to achieve minimal carbon emission for environmental concern. The authors of [15] optimized the operations of CHP plants for economic benefit in a deregulated electricity market. Heat storage was used for maximum electricity production during high price period, whose operations strategy was determined based on forecasted loads, electricity prices and operational costs. An optimization model based on mixed-integer linearprogramming is used to calculate the optimal operational strategy for CHP plant and storage, and different investment potentials are obtained according to the strategy selected. Reference [16] studied a similar problem without considering the electricity market dynamics, with the only objective being the minimization of total costs over the planning period. Reference [20] used receding horizon optimization approach to optimize the operations of HRES, with the objective of meeting electricity demand while achieving minimum overall operating and environmental costs. Model predictive controls were used by [21] to operate a HRES with both PV and diesel generation, for optimal technical performance. Operations optimization of distributed energy systems were studied in [3537], where [35] considers also the exergy efficiency in the optimization process, while $[36,37]$ formulates a multiobjective optimization approach to manage electrical energy storage systems or shiftable loads to minimize the energy loss in the grid, the total electricity generation cost, and the GHG emissions. Reference [38] reviews different optimizations methods that have been applied to renewable and sustainable energy systems, including wind, solar, hydropower, bioenergy, geothermal, and hybrid systems.

The study carried out in this paper is unique in the following aspects: (1) the HES considered here integrates not only multiple energy inputs, but also multiple energy outputs, thus different from either CHP or HRES studied in literature; (2) the operations optimization formulated here considers various markets for electric and non-electric products and also for feedstock procurement; (3) different temporal scales are investigated for deregulated electricity market (both day-ahead market and real-time market).

\section{Notations and Preliminaries}

\subsection{HES configuration}

Without loss of generality, the HES considered here include one CER (denoted as Primary Heat Generation $[\mathrm{PHG}]$ ), one VER that is modeled as renewable energy input (denoted as REN), and one APP. The methodology developed herein can be straightforwardly extended to HES with multiple CER, VER, and/or APP. Fig. 4 shows the architectural topology of considered HES, consisting of two Energy Storage Elements (ESE), one used for power smoothing to attenuate renewable variability and the other used to maintain energy balance within HES. Depending on different applications, APP may require process steam and/or electricity for production. Likewise, an Auxiliary Heat Generation (AHG) may be used to provide additional on-demand steam for APP if required.

Electricity generated by PC is combined with that generated from REN, and delivered to the electric grid. At 


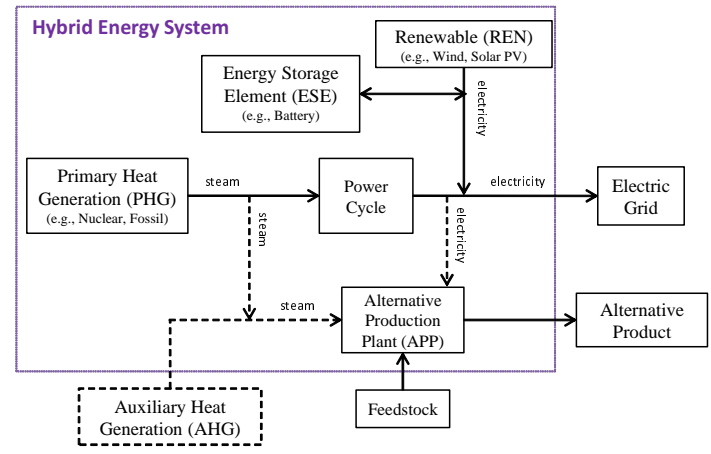

Figure 4: Architectural topology of considered HES in this work.

any time, the energy distribution between the electricity delivered to the grid versus the energy delivered to APP is determined by the operations optimizer, which maximizes the economic value of HES under the constraints imposed by system dynamics. For instance, the energy delivered to APP may need to be within a specified range in order to maintain its required minimum and maximum turndowns. Furthermore, in the case that HES provides ancillary service to the electric grid, the energy delivered to APP needs to be greater than the capacity agreed upon as ancillary service to ensure its availability in case it is called for.

\subsection{Optimization methodology}

The standard form of a constrained optimization problem is given as follows:

$$
\begin{array}{lll}
\operatorname{minimize} & f(x) & \\
\text { subject to } & g_{i}(x) \leq 0 & i=1, \ldots, k \\
& h_{i}(x)=0 & i=1, \ldots, p
\end{array}
$$

where $f(x): \mathbb{R}^{n} \rightarrow \mathbb{R}$ is the objective function to be minimized over decision variables $x$, with $n=|x|$ generally greater than $1, g_{i}(x) \leq 0, i=1, \ldots, k$ is the set of $k$ inequality constraints, and $h_{i}(x)=0, i=1, \ldots, p$ is the set of $p$ equality constraints.

To solve this general optimization problem, one needs to design an algorithm that iteratively adjusts the values of decision variables and terminates only when certain conditions (e.g., Karush-Kuhn-Tucker conditions [39]) regarding the values of objective function and constraints are met. Numerous algorithms have been developed, including gradient-based methods [40], gradient-free methods [41], as well as hybrid approaches [42]. When selecting an appropriate algorithm for optimization, it is critical to match the algorithm to the mathematical properties of the optimization problem, such as the nature of objective function and constraints [4]. As can be seen later in Section 4 and 5, the objective function and constraints in this study are all convex. Accordingly, fmincon function included in Matlab Optimization Toolbox is selected, which is an implementation of the interior-point method [43] that aims at solving linear and nonlinear convex optimization problems.

\section{Economic Functions}

In this work, three economic figures of merit (FOM) are used as the objective functions for operations optimization and economic evaluation, including:

Net present value. NPV is defined as follows [44]:

$$
N P V=\sum_{k=0}^{N} \frac{F C F F_{R, k}}{\left(1+r_{R}\right)^{k}}
$$

where $N$ is the years of operations of HES, $r_{R}$ denotes discount rate (assumed to be $5 \%$ ) used in computing weighted average cost of capital (WACC), and $F C F F_{R, k}$, the real discounted Free Cash Flow to Firm for year $k$, equals

$$
\begin{aligned}
F C F F_{R, k} & =\left(R_{k}-C_{O \& M, k}-D A_{k}(1+i)^{-k}\right)(1-\sigma) \\
& +D A_{k}(1+i)^{-k}-C_{g h g, k}-C A P E X_{k}
\end{aligned}
$$

where $\sigma$ is tax rate, and $i$ is inflation rate (assumed to be $3 \%$ ). $C A P E X_{k}$ (capital expense) only occurs when $k=0$, i.e., year 0 , given by $C A P E X_{0}=C_{c a p}$, and $C A P E X_{k}=0$ for all $k>0$. The capital cost $C_{c a p}$, operations and maintenance $(\mathrm{O} \& \mathrm{M})$ cost $C_{O \& M, k}$, cost for greenhouse gas (GHG) emission $C_{g h g, k}$, and revenue $R_{k}$, for year $k$, are given in the following sections by equations (5), (6), (9), and (10), respectively. Depreciation and amortization (DA) for year $k$ for tax deduction under Modified Accelerated Cost Recovery Systems, i.e., $D A_{k}$ in (2), is calculated by $D A_{k}=\rho_{d a, k} C_{c a p}$, where $\rho_{d a, k}$ is the DA rates $^{1}$ at year $k$.

Payback period. Payback period, $T_{p b}$, refers to the period of time required to recoup the expense of an investment [46]. For a fixed discount rate, it is defined as the years of operations such that NPV equals 0, i.e.,

$$
T_{p b}=\arg _{N}[N P V=0] .
$$

Internal rate of return. IRR, also called effective interest rate, is used to measure and compare the profitability of investments, and is defined as, for a fixed $N$ years of operations, the value of $r_{R}$ such that NPV equals 0 [47], i.e.,

$$
I R R=\arg _{r_{R}}[N P V=0] .
$$

Next, we formulate several economic functions that are necessary for computing the three economic FOMs introduced above. For simplicity of presentation, only spot market will be considered for feedstock and alternative product, while one forward market and one spot market

\footnotetext{
${ }^{1} \rho_{d a, k}$ for $k \leq 16$, i.e., the first 16 years, are $5.00 \%, 9.50 \%$, $8.55 \%, 7.70 \%, 6.93 \%, 6.23 \%, 5.90 \%, 5.90 \%, 5.91 \%, 5.90 \%, 5.91 \%$, $5.90 \%, 5.91 \%, 5.90 \%, 5.91 \%, 2.95 \%$, respectively, and $0 \%$ afterwards [45]. Note that the Modified Accelerated Cost Recovery Systems use a life time of 16 years for calculating DA. The actual use life doesn't have to be 16 years. The proposed methodology here is flexible to accommodate different DA scenarios.
} 
will be considered for electricity. The economic functions and also the optimization methodology developed herein can be readily extended to consider multiple forward markets for each product. Note also that, while some variables are varying with respect to time $t$, they are denoted without subscript $t$ when there is no confusion.

\subsection{Capital cost}

The capital cost $C_{c a p}$ associated with building considered HES includes costs relevant to PHG (including PC), AHG (optional), APP, REN, and ESE as follows:

$$
C_{c a p}=C_{p h g}+C_{a h g}+C_{a p p}+C_{r e n}+C_{e s e} .
$$

The capital cost for PHG (including PC) is calculated by $C_{p h g}=\alpha_{p h g} \mathcal{N}_{p h g}$, where $\alpha_{p h g}$ is the capital cost per unit of installed capacity and $\mathcal{N}_{p h g}$ denotes the installed capacity of PHG (i.e., the rated maximal output power in this case). Similar equations are formulated for computing $C_{a h g}, C_{a p p}, C_{r e n}$, and $C_{e s e}$ by replacing the subscript "phg" with ahg, app, ren, and ese, respectively.

\subsection{Operations and maintenance cost}

The O\&M cost $C_{O \& M, k}$ for year $k$ can be further divided into fixed $\mathrm{O} \& \mathrm{M}$ cost $\left(O \& M_{f}\right)$ and variable $\mathrm{O} \& \mathrm{M}$ cost $\left(O \& M_{v}\right)$, i.e.,

$$
C_{O \& M, k}=O \& M_{f}+O \& M_{v} .
$$

Note that $O \& M_{f}$ includes O\&M cost that is relatively constant with respect to operations, while $O \& M_{v}$ essentially corresponds to the cost of fuel and feedstock. Similar to capital cost, $O \& M_{f}$ and $O \& M_{v}$ are also grouped with respect to each HES constituent, as following:

$$
\begin{aligned}
O \& M_{f}= & O \& M_{f_{-} p h g}+O \& M_{f_{-} a h g}+O \& M_{f_{-} a p p} \\
& +O \& M_{f_{\_} r e n}+O \& M_{f_{-} e s e} \\
O \& M_{v}= & O \& M_{v_{-} a h g}+O \& M_{v_{-} a p p},
\end{aligned}
$$

with $O \& M_{f_{-} a h g}$ and $O \& M_{v_{-} a h g}$ being optional (depending on specific HES configuration). Note that REN and ESE do not incur any variable O\&M cost as there is no feedstock required for their operations. Meanwhile, the variable O\&M cost for PHG is not formulated either since PHG, as baseload generation, is operated in relatively constant mode.

The fixed O\&M cost for PHG is calculated as $O \& M_{f_{-} p h g}=\beta_{f_{-} p h g} C_{p h g}$, where $\beta_{f_{-} p h g}$ is used to indicate that the (annual) fixed O\&M cost for operating PHG is a fraction of its capital cost. Similar equations are formulated for computing $O \& M_{f_{-} a h g}, O \& M_{f_{-} a p p}, O \& M_{f_{-} r e n}$, and $O \& M_{f_{-} e s e}$ by replacing the subscript "phg" with $a h g$, app, ren, and ese, respectively.

The variable O\&M cost for APP is calculated by:

$$
O \& M_{v_{-} a p p}=\sum_{n=1}^{N_{a p p}} \int_{0}^{T} \beta_{v_{-} a p p, n} M_{v_{-} a p p, n} d t
$$

where $T$ is the considered time period (e.g., a year), $M_{v_{-} a p p, n}$ and $\beta_{v_{-} a p p, n}$ are the consuming rate and price of $n$th feedstock. Similar equation for AHG is formulated by replacing the subscript "app" with " $a h g$ ".

\subsection{Greenhouse gas emission cost}

GHG emission cost is associated with the taxation imposed on GHG emission and/or cost to capture and store GHG. Since $\mathrm{CO}_{2}$ is the dominant GHG, this cost is essentially made equal to the $\mathrm{CO}_{2}$ cost, computed as follows:

$$
C_{g h g, k}=\int_{0}^{T} \beta_{\mathrm{Co}_{2}} M_{\mathrm{Co}_{2}} d t
$$

where $\beta_{\mathrm{Co}_{2}}$ is the taxation rate over $\mathrm{CO}_{2}$ and $M_{\mathrm{Co}_{2}}$ is the combined $\mathrm{CO}_{2}$ emission rate by all components within HES. Depending on different HES configurations, $\mathrm{CO}_{2}$ emission can come from either PHG, AHG, or APP.

\subsection{Electric power market}

As described above, HES considered here produces electricity as well as alternative product. As demonstrated in $[5,6]$, HES can additionally bid into ancillary service market to provide ancillary service including spinning and nonspinning reserve to support grid stability. A common practice used by system operator in deregulated power market is the two-settlement process, which consists of day-ahead market (DAM) and real-time market (RTM) [48]. DAM is a forward market in which the offers and bids on electrical energy and ancillary service are placed for each hour of the next day. DAM would be cleared and closed before the delivery date, and the participants are paid (or charged) at bid (or offer) price if the market is a bilateral one or at the market clearing price in case of a pool market. On the other hand, to allow system operator to balance the difference between day-ahead generation commitment and the actual real-time demand, RTM, being a spot market, allows market participants to buy and sell wholesale electrical energy and ancillary service during the course of the operating day, with delivery time near "real-time" (e.g., within one hour). Depending on different market designs, the delivery period can be half hour, quarter hour, or even five minutes. This paper considers a typical RTM with delivery period being 15 minutes.

In this paper, we consider HES participating in DAM to sell electrical energy and ancillary service, as well as in RTM to sell electrical energy. Denote $R_{d a, e}$ as the revenue from sale of electrical energy in DAM, given by:

$$
R_{d a, e}=\int_{0}^{T} \pi_{d a, e} P_{d a, e} d t
$$

where $\pi_{d a, e}$ is the price of electrical energy in DAM and $P_{d a, e}$ is the amount of power sold in DAM, both potentially varying with time. Similar equations are formulated for computing $R_{d a, a s}$ (revenue from sale of ancillary services in DAM) and $R_{r t}$ (revenue from sale of electrical energy in 
RTM), by replacing the subscript " $d a, e$ " with " $d a, a s "$ and " $r t$ ", respectively. Note that when the ancillary service is called for, the energy delivered as ancillary service will be remunerated at real-time price $\pi_{r t}$. This "hidden" revenue is implicitly included in $R_{d a, a s}$ as shown in Section 5 .

\subsection{Commodity market}

HES also participates in wholesale market for selling alternative product. Denote $R_{a p p}$ as this revenue and

$$
R_{a p p}=\int_{0}^{T} \pi_{a p p} M_{a p p} d t
$$

where $\pi_{a p p}$ is the price of alternative product and $M_{a p p}$ is its production rate. Finally, the revenue $R_{k}$ for year $k$ is given by:

$$
R_{k}=R_{d a, e}+R_{d a, a s}+R_{r t}+R_{a p p}
$$

\section{Economic Optimization of Operations}

It is not hard to see that, maximizing the NPV defined in (1), minimizing the payback period $T_{p b}$ defined in (3), and maximizing the IRR defined in (4), are all equivalent to maximizing the $F C F F_{R, k}$ defined in (2) for each year $k$ (assuming system design is fixed). By dropping from (2) the terms that are constant with respect to operations, which include $O \& M_{f}, C A P E X_{k}$, and terms related to $D A_{k}$, the objective function for operations optimization is thus formulated as:

$$
J=\left(R_{k}-O \& M_{v}\right)(1-\sigma)-C_{g h g, k} .
$$

Note that $J$ is defined over the period of one year for each $k$, referred as annual objective function. For the simplicity of presentation, we omit the subscript of $J$. By expanding (11) using (8), (9), and (10), $J$ can be expressed as:

$$
\begin{aligned}
J= & (1-\sigma) \int_{0}^{T}\left[\pi_{d a, e} P_{d a, e}+\left(\pi_{d a, a s}+p_{a s} \pi_{r t}\right) P_{d a, a s}\right. \\
& +\pi_{r t} P_{r t}+\pi_{a p p} M_{a p p}-\sum_{n=1}^{N_{a p p}} \beta_{v_{-} a p p, n} M_{v_{-} a p p, n} \\
& \left.-\sum_{n=1}^{N_{a h g}} \beta_{v_{-} a h g, n} M_{v_{-} a h g, n}\right] d t-\int_{0}^{T} \beta_{c o_{2}} M_{c o s_{2}} d t .
\end{aligned}
$$

Note in the above formulation, the revenue from sale of AS in DAM also includes the remuneration $\int_{0}^{T} p_{a s} \pi_{r t} P_{d a, a s} d t$ for the energy delivered as AS if it is called for, where $p_{a s}$ is the probability that the reserved capacity will be called for. At any time, the energy within HES needs to be balanced between generations and loads, i.e.,

$$
P_{a p p}+P_{d a, e}+P_{r t}=P_{p h g}+P_{r e n},
$$

where $P_{\text {ren }}$ and $P_{p h g}$ are power generated by REN and PHG, respectively, and $P_{a p p}$ is the power generated by
PHG and delivered to $\mathrm{APP}^{2}$. When an AHG is used to supplement the energy supply to APP, the generation from AHG is solely consumed by APP as can be seen in Fig. 4. Hence this pair of generation and consumption is exactly balanced, and is omitted in (13). Furthermore, as illustrated in Section 3.1, $P_{a p p}$ needs to be between the maximum and minimum turndowns of APP, and the reserved capacity sold as ancillary service cannot exceed the maximum flexibility of $P_{a p p}$. Consequently, the following constraints are established:

$$
\begin{gathered}
P_{a p p}^{L} \leq P_{a p p} \leq P_{a p p}^{U} \\
P_{d a, a s} \leq P_{a p p}-P_{a p p}^{L},
\end{gathered}
$$

where $P_{a p p}^{L}$ and $P_{a p p}^{U}$ are the minimum and maximum power consumed by APP that must be provided by PHG (hence excluding the contribution of AHG). Finally, depending on different HES configurations, there can be a number (assumed to be $L$ ) of constraints over decision variables (i.e., production rate, feedstock consumption rate, etc), presented as following, for $i=1, \ldots, L$ :

$$
\begin{aligned}
& h_{i}\left(P_{d a, e}, P_{d a, a s}, P_{r t}, M_{v_{-} a p p, 1}, \ldots, M_{v_{-} a p p, N_{a p p}}\right. \\
& \left.\quad M_{v_{-} a h g, 1}, \ldots, M_{v_{\_} a h g, N_{a h g}}, M_{a p p}, M_{c o_{2}}\right)=0 .
\end{aligned}
$$

Hence, the optimization problem is formulated as:

$$
\begin{array}{ll}
\text { maximize } & J \text { as in }(12) \\
\text { subject to } & (13)-(16) \\
& P_{d a, e}, P_{d a, a s}, P_{r t} \text { are nonnegative. }
\end{array}
$$

As shown in Fig. 3, the above optimization problem is addressed by iteratively maximizing (12) with respect to each forward markets and spot market. In this work, without loss of generality, only spot market is considered for feedstock and alternative product, while one forward market (i.e., DAM) and one spot market (i.e., RTM) are considered for electricity. In the following sections, two operations optimizers are introduced, one for DAM and one for RTM. The optimizer for DAM, denoted as DAO (day-ahead optimizer), maximizes (12) by computing the optimal amounts of energy and AS capacity sold in DAM, as well as the amount of energy held to participate in RTM. It is assumed that the pricing information of alternative commodity and feedstock, and that in DAM are all well known, while the price information in RTM and the renewable generation available on the delivery date need to be estimated by DAO. On the other hand, the optimizer for RTM, denoted as RTO (real-time optimizer), maximizes (12) by computing the optimal amount of energy sold in RTM, based on additional constraints imposed by the optimization results of DAO. It is assumed that the price information in RTM and renewable generation are both well known by RTO.

${ }^{2}$ For simplicity, all power calculations will be expressed using the electrical equivalence (in MW) of the particular power stream, assuming fixed thermal-to-electrical conversion efficiency. 


\subsection{Optimization for day-ahead market}

For each hour interval, the objective function for DAO is given as, by expanding (12),

$$
\begin{aligned}
J_{d a} & =(1-\sigma) \int_{0}^{\Delta T}\left[\pi_{d a, e} P_{d a, e}+\left(\pi_{d a, a s}+p_{a s} \widetilde{\pi}_{r t}\right) P_{d a, a s}\right. \\
& +\widetilde{\pi}_{r t} P_{d a, r t}+\pi_{a p p} \widetilde{M}_{a p p}-\sum_{n=1}^{N_{a p p}} \beta_{v_{-} a p p, n} \widetilde{M}_{v_{-} a p p, n} \\
& \left.-\sum_{n=1}^{N_{a h g}} \beta_{v_{-} a h g, n} \widetilde{M}_{v_{-} a h g, n}\right] d t-\int_{0}^{\Delta T} \beta_{c o_{2}} \widetilde{M}_{c o s_{2}} d t,
\end{aligned}
$$

where $\Delta T$ is one hour interval, $P_{d a, r t}$ is the amount of power held to participate in RTM, and notation ? means the prediction of corresponding variables. The decision variables considered by DAO are $P_{d a, e}, P_{d a, a s}$, $P_{d a, r t}, \widetilde{M}_{a p p}, \widetilde{M}_{v_{-} a p p, n}, n=1, \ldots, N_{a p p}, \widetilde{M}_{v_{-} a h g, n}, n=$ $1, \ldots, N_{a h g}$. Likewise, constraints (13) - (16) can be represented as follows:

$$
\begin{gathered}
\widetilde{P}_{a p p}+P_{d a, e}+P_{d a, r t}=P_{p h g}+\widetilde{P}_{r e n} \\
P_{a p p}^{L} \leq \widetilde{P}_{a p p} \leq P_{a p p}^{U} \\
P_{d a, a s} \leq \widetilde{P}_{a p p}-P_{a p p}^{L} \\
h_{i}\left(P_{d a, e}, P_{d a, a s}, P_{d a, r t}, \widetilde{M}_{v_{-} a p p, 1}, \ldots, \widetilde{M}_{v_{-} a p p, N_{a p p}}\right. \\
\left.\widetilde{M}_{v_{-} a h g, 1}, \ldots, \widetilde{M}_{v_{-} a h g, N_{a h g}}, \widetilde{M}_{a p p}, \widetilde{M}_{c o_{2}}\right)=0 .
\end{gathered}
$$

Combining (18) and (19) gives $P_{a p p}^{L} \leq P_{p h g}+\widetilde{P}_{r e n}-P_{d a, e}-$ $P_{d a, r t} \leq P_{a p p}^{U}$, or equivalently

$P_{p h g}+\widetilde{P}_{r e n}-P_{a p p}^{U} \leq P_{d a, e}+P_{d a, r t} \leq P_{p h g}+\widetilde{P}_{r e n}-P_{a p p}^{L}$.

Similarly, combining (18) and (20) gives $P_{d a, a s} \leq P_{p h g}+$ $\widetilde{P}_{r e n}-P_{d a, e}-P_{d a, r t}-P_{a p p}^{L}$, or equivalently

$$
P_{d a, e}+P_{d a, a s}+P_{d a, r t} \leq P_{p h g}+\widetilde{P}_{r e n}-P_{a p p}^{L} .
$$

Since $P_{d a, e}, P_{d a, a s}$ and $P_{r t}$ can change value only on the hour, to ensure that the above constraints (22) and (23) are satisfied within the entire period of each hour, the following equivalent constraints are obtained:

$$
\begin{array}{r}
P_{p h g}+\widetilde{P}_{r e n}^{U}-P_{a p p}^{U} \leq P_{d a, e}+P_{d a, r t} \leq P_{p h g}+\widetilde{P}_{r e n}^{L}-P_{a p p}^{L} \\
(24) \\
P_{d a, e}+P_{d a, a s}+P_{d a, r t} \leq P_{p h g}+\widetilde{P}_{r e n}^{L}-P_{a p p}^{L},
\end{array}
$$

where $\widetilde{P}_{\text {ren }}^{U}$ and $\widetilde{P}_{r e n}^{L}$ are the maximum and minimum of the predicted renewable generation within the hour. Furthermore, it is also assumed that the capacity sold as AS and the energy held for RTM cannot exceed certain limits, denoted as $P_{d a, a s}^{U}$ and $P_{d a, r t}^{U}$, respectively. Therefore,

$$
\begin{aligned}
& 0 \leq P_{d a, a s} \leq P_{d a, a s}^{U} \\
& 0 \leq P_{d a, r t} \leq P_{d a, r t}^{U} .
\end{aligned}
$$

Finally, we have

$$
P_{d a, e} \geq 0 \text {. }
$$

The optimization problem for DAM is then given as:

$$
\begin{array}{ll}
\text { maximize } & J_{d a} \text { as in }(17) \\
\text { subject to } & (18),(21),(24)-(28)
\end{array}
$$

Remark 1. The above optimization problem is solved by the methodology introduced in Section 3.2 for each one hour interval. Note that this optimization problem is feasible only if $P_{p h g}+\widetilde{P}_{r e n}^{L}-P_{a p p}^{L} \geq P_{p h g}+\widetilde{P}_{r e n}^{U}-$ $P_{a p p}^{U}$, and so, $\widetilde{P}_{r e n}^{U}-\widetilde{P}_{r e n}^{L} \leq P_{a p p}^{U}-P_{a p p}^{L}$. Since $\widetilde{P}_{r e n}^{U}-\widetilde{P}_{r e n}^{L}$ cannot be greater than the capacity of REN, i.e., $\widetilde{P}_{r e n}^{U}-$ $\widetilde{P}_{\text {ren }}^{L} \leq \mathcal{N}_{\text {ren }}$, for the above optimization problem to be feasible, it suffices to design HES so that $P_{a p p}^{U}-P_{a p p}^{L} \geq \mathcal{N}_{\text {ren }}$, i.e., the capacity of REN is no larger than the difference between $P_{a p p}^{U}$ and $P_{a p p}^{L}$.

\subsection{Optimization for real-time market}

Similar to (17), for each quarter hour interval, the objective function for RTO is given as, by expanding (12),

$$
\begin{aligned}
J_{r t}= & (1-\sigma) \int_{0}^{\Delta T}\left[\pi_{d a, e} P_{d a, e}+\left(\pi_{d a, a s}+p_{a s} \pi_{r t}\right) P_{d a, a s}\right. \\
& +\pi_{r t} P_{r t}+\pi_{a p p} M_{a p p}-\sum_{n=1}^{N_{a p p}} \beta_{v_{-} a p p, n} M_{v_{-} a p p, n} \\
& \left.-\sum_{n=1}^{N_{a h g}} \beta_{v_{-} a h g, n} M_{v_{-} a h g, n}\right] d t-\int_{0}^{\Delta T} \beta_{c o_{2}} M_{c o s_{2}} d t,
\end{aligned}
$$

where, with a slight abuse of notation, $\Delta T$ is a quarter hour interval, and $P_{r t}$ is the amount of electricity sold in RTM. Since RTM is operated near "real time", i.e., the delivery time is within one hour after transaction time, both renewable generation and real-time electricity price are assumed to be perfectly known to RTO. The decision variables considered by RTO are $P_{r t}, M_{a p p}, M_{v_{-} a p p, n}$, $n=1, \ldots, N_{a p p}, M_{v_{a} a h g, n}, n=1, \ldots, N_{a h g}$, and $M_{a h g, c_{2}}$. Since in this case DAM has been closed and all transactions are cleared, $P_{d a, e}$ and $P_{d a, a s}$ are no longer variables and their values throughout the course of the day are. Likewise, constraints (13) - (16) can be reformulated as follows:

$$
\begin{gathered}
P_{a p p}+P_{d a, e}+P_{r t}=P_{p h g}+P_{r e n} \\
P_{a p p}^{L} \leq P_{a p p} \leq P_{a p p}^{U} \\
P_{d a, a s} \leq P_{a p p}-P_{a p p}^{L} \\
h_{i}\left(P_{d a, e}, P_{d a, a s}, P_{d a, r t}, M_{v_{-} a p p, 1}, \ldots, M_{v_{-} a p p, N_{a p p}}\right. \\
\left.M_{v_{\_} a h g, 1}, \ldots, M_{v_{-} a h g, N_{a h g}}, M_{a p p}, M_{c o_{2}}\right)=0 .
\end{gathered}
$$

Combining (30) and (31) gives $P_{a p p}^{L} \leq P_{p h g}+P_{r e n}-P_{d a, e}-$ $P_{r t} \leq P_{a p p}^{U}$, or equivalently

$P_{p h g}+P_{r e n}-P_{d a, e}-P_{a p p}^{U} \leq P_{r t} \leq P_{p h g}+P_{r e n}-P_{d a, e}-P_{a p p}^{L}$. 
Similarly, combining (30) and (32) gives $P_{d a, a s} \leq P_{p h g}+$ $P_{r e n}-P_{d a, e}-P_{r t}-P_{a p p}^{L}$, or equivalently

$$
P_{r t} \leq P_{p h g}+P_{r e n}-P_{d a, e}-P_{d a, a s}-P_{a p p}^{L} .
$$

Since $P_{r t}$ can change value only on the top of every quarter hour, to ensure that the above constraints (34) and (35) are held within the entire period of each quarter hour, the following equivalent constraints are obtained:

$$
\begin{array}{r}
P_{p h g}+P_{r e n}^{U}-P_{d a, e}-P_{a p p}^{U} \leq P_{r t} \leq P_{p h g}+P_{r e n}^{L}-P_{d a, e}-P_{a p p}^{L} \\
P_{r t} \leq P_{p h g}+P_{r e n}^{L}-P_{d a, e}-P_{d a, a s}-P_{a p p}^{L},
\end{array}
$$

where $P_{\text {ren }}^{U}$ and $P_{\text {ren }}^{L}$ are the maximum and minimum of the renewable generation within that quarter hour. For simplicity, the possibility of buying energy in RTM (to compensate the short on generation due to overestimation of renewable energy) is not considered. Therefore

$$
P_{r t} \geq 0
$$

Furthermore, when real-time price of electricity is nonpositive, none of the electricity should be sold. Thus,

$$
P_{r t}=0 \text { if } \pi_{r t} \leq 0 \text {. }
$$

The optimization problem for RTM is then given as:

$$
\begin{array}{ll}
\text { maximize } & J_{r t} \text { as in }(29) \\
\text { subject to } & (30),(33),(36)-(39)
\end{array}
$$

Remark 2. To check the feasibility of this optimization problem, define

$$
\begin{aligned}
& B_{1}:=P_{p h g}+P_{r e n}^{U}-P_{d a, e}-P_{a p p}^{U} \\
& B_{2}:=P_{p h g}+P_{r e n}^{L}-P_{d a, e}-P_{a p p}^{L} \\
& B_{3}:=P_{p h g}+P_{r e n}^{L}-P_{d a, e}-P_{d a, a s}-P_{a p p}^{L} .
\end{aligned}
$$

It can be verified that $B_{2} \geq B_{1}$ and $B_{2} \geq B_{3}$, and so the feasible condition is given by:

- When $\pi_{r t}>0$, then it is feasible only if $\min \left(B_{2}, B_{3}\right) \geq$ $\max \left(0, B_{1}\right)$, which in turn requires

$$
B_{3} \geq \max \left(0, B_{1}\right) \text {. }
$$

- When $\pi_{r t} \leq 0$, then it is feasible only if $\min \left(0, B_{2}, B_{3}\right) \geq \max \left(0, B_{1}\right)$, which in turn requires

$$
B_{1} \leq 0 \leq B_{3} .
$$

When the above optimization problem is feasible, it is solved by the methodology introduced in Section 3.2 for each quarter hour interval. However, due to prediction errors, this optimization problem may not always be feasible. In this case any operations in RTM will violate either (36) or (37), so a standby ESE is needed to ensure energy balance within HES, as discussed next.

\subsection{Control strategy to accommodate prediction errors}

This section discusses the control strategy to ensure the correct function of HES in case (40) or (41) is violated, by properly operating a standby ESE. We first discuss the physical indication of violation of (36) or (37).

- If $P_{r t}$ is lower than $B_{1}$, violating the first inequality of (36), then at some point during the period of quarter hour, $P_{a p p}^{U}<P_{p h g}+P_{r e n}-P_{d a, e}-P_{r t}=P_{a p p}$, i.e., the power sent to APP exceeds its capacity. In this case, this excess power needs to be dynamically diverted to the standby ESE for charging, to ensure $P_{a p p} \leq P_{a p p}^{U}$.

- If $P_{r t}$ is higher than $B_{2}$, violating the second inequality of (36), then at some point during the period of quarter hour, $P_{a p p}^{L}>P_{p h g}+P_{r e n}-P_{d a, e}-P_{r t}=P_{a p p}$, i.e., the power sent to APP is lower than its minimum turndown. In this case, additional power is needed from dynamically discharging the standby ESE to ensure $P_{a p p} \geq P_{a p p}^{L}$.

- If $P_{r t}$ is higher than $B_{3}$, violating (37), then at some point during the period of quarter hour, $P_{d a, a s}>$ $P_{p h g}+P_{r e n}-P_{d a, e}-P_{r t}-P_{a p p}^{L}=P_{a p p}-P_{a p p}^{L}$, i.e., the ancillary service capacity committed to the electric grid is greater than the flexible capacity that can be provided by varying the operations of APP. This would result in a risk to fail to deliver the committed reserve capacity when it is called for. Therefore, additional power is needed from dynamically discharging the standby ESE to ensure $P_{a p p}-P_{a p p}^{L} \geq P_{d a, a s}$. However, since this essentially presents the case of selling more electricity by using backup power from the standby ESE, violation of (37) should be avoided whenever possible.

Next we present the control strategy when $\pi_{r t}>0$ and condition (40) is not satisfied, according to following cases:

1. Both $B_{1} \leq 0$ and $B_{3}<0$ : In this case, by setting $P_{r t}=0$, the first inequality of (36) is satisfied and (37) is violated. Furthermore:

- If $B_{2} \geq 0$, then the second inequality of (36) is satisfied. In this case, the standby ESE needs to be properly discharged to ensure $P_{a p p}-P_{a p p}^{L} \geq$ $P_{d a, a s}$ is satisfied all the time;

- If $B_{2}<0$, then the second inequality of (36) is violated. In this case, the standby ESE needs to be properly discharged to ensure $P_{a p p}-P_{a p p}^{L} \geq$ $P_{d a, a s}$ and $P_{a p p} \geq P_{a p p}^{L}$ are both satisfied all the time.

2. $0 \leq B_{3}<B_{1}$ : There are two possible control strategies in this case: (I) Set $P_{r t}=B_{3}$, leaving only the first inequality of (36) violated. As discussed above, the standby ESE needs to be properly charged to ensure $P_{a p p} \leq P_{a p p}^{U}$ is satisfied all the time. (II) Set $P_{r t}=B_{1}$, leaving only (37) violated. As discussed above, the standby ESE needs to be properly discharged to ensure $P_{a p p}-P_{a p p}^{L} \geq P_{d a, a s}$ is satisfied 
Table 1: Resilient control strategy when (40) or (41) is violated

\begin{tabular}{|l|l|l|}
\hline Conditions & $P_{r t}$ & Operations on standby ESE \\
\hline$\pi_{r t}>0, B_{1} \leq 0, B_{3}<0$ & 0 & discharge \\
\hline$\pi_{r t}>0,0 \leq B_{3}<B_{1}$ & $B_{3}$ & charge \\
\hline$\pi_{r t}>0, B_{1}>0, B_{3}<0$ & 0 & charge \& discharge \\
\hline$\pi_{r t} \leq 0, B_{1}>0$ & 0 & charge \\
\hline$\pi_{r t} \leq 0, B_{3}<0 \leq B_{2}$ & 0 & discharge \\
\hline$\pi_{r t} \leq 0, B_{3} \leq B_{2}<0$ & 0 & discharge \\
\hline
\end{tabular}

all the time. Due to the instability introduced by the second option, RTO sets $P_{r t}=B_{3}$ and control to charge the standby ESE accordingly.

3. $B_{1}>0$ and $B_{3}<0$ : There are also two possible control strategies in this case: (I) Set $P_{r t}=0$, violating both the first inequality of (36) and (37). As discussed above, the standby ESE needs to be properly charged and discharged (at different time instance) to ensure both $P_{a p p} \leq P_{a p p}^{U}$ and $P_{a p p}-P_{a p p}^{L} \geq P_{d a, a s}$ are satisfied all the time. (II) Set $P_{r t}=B_{1}$, leaving only (37) violated. As discussed above, the standby ESE needs to be properly discharged to ensure $P_{a p p}-P_{a p p}^{L} \geq P_{d a, a s}$ is satisfied all the time. While both options violate condition (37), the second option results in a deeper violation in terms of larger $P_{r t}-B_{3}$, putting HES in higher risk. Thus in this case, RTO sets $P_{r t}=0$ and control to charge and discharge the standby ESE (at different time instance) accordingly.

On the other hand, when $\pi_{r t} \leq 0$ and condition (41) is not satisfied, then $P_{r t}$ is set to 0 . Moreover

1. If $B_{1}>0$, then the first inequality of (36) is violated, and the standby ESE needs to be properly charged to ensure $P_{a p p} \leq P_{a p p}^{U}$ is satisfied all the time.

2. If $B_{3}<0 \leq B_{2}$, then (37) is violated, and the standby ESE needs to be properly discharge to ensure $P_{a p p}-$ $P_{a p p}^{L} \geq P_{d a, a s}$ is satisfied all the time.

3. If $B_{3} \leq B_{2}<0$, then both the second inequality of (36) and (37) are violated, and the standby ESE needs to be properly discharged to ensure $P_{a p p}-P_{a p p}^{L} \geq$ $P_{d a, a s}$ and $P_{a p p} \geq P_{a p p}^{L}$ are both satisfied all the time.

Table 1 summarizes the control strategy discussed above.

\section{Numerical Results and Discussions}

This section presents numerical results of the optimization introduced in previous section, by applying on two specific HES configurations taken from $[5,6]$.

\subsection{Hybrid Energy System with Flexible Thermal Load}

The first configuration, termed as HES_FTL (hybrid energy system with flexible thermal load), includes the following primary components:
- PHG: a nuclear reactor and a steam generator;

- PC: a Rankine cycle consisting of steam generator, turbines, electric generator, condenser, feedwater pumps and heaters, producing electricity up to 180 $\mathrm{MW}$;

- REN: a series of wind turbines with total wind plant capability of up to $45 \mathrm{MW}$;

- ESE: two electrical batteries, one to attenuate variability of the electricity generated by renewable source, and the other to compensate prediction error;

- AHG: a natural gas (NG) boiler of up to $45 \mathrm{MW}$ capacity that generates additional on demand steam;

- APP: a gasoline production plant (GPP) able to utilize up to $45 \mathrm{MW}$ and convert NG and water into gasoline (and liquefied petroleum gas).

In this case, a GPP is used as APP, which requires process steam as its energy supplies. An NG-based AHG is used to supplement the energy supplies to GPP to maintain its production rate at its maximum capacity. Due to the presence of AHG, the energy supply from PHG to GPP can be as low as zero, hence $P_{a p p}^{L}=0 \mathrm{MW}$ and $P_{a p p}^{U}=45 \mathrm{MW}$ for GPP. Since APP consumes two types of feedstock, i.e., water and $\mathrm{NG}$, for gasoline production, we have $N_{a p p}=2$, with $\beta_{v_{-} a p p, 1}$ being water price and $\beta_{v_{-} a p p, 2}$ being NG price. Similarly, AHG consumes only one type of feedstock, i.e., $\mathrm{NG}$, so $N_{a h g}=1$, with $\beta_{v_{-} a h g, 1}$ being NG price. For HES_FTL, the equality constraints (16) can be rewritten $\mathrm{as}^{3}$ :

$$
\begin{gathered}
M_{v_{\_} a h g, 1}=k_{0}+k_{1}\left(P_{d a, e}+p_{a s} P_{d a, a s}+P_{d a, r t}-P_{r e n}\right) \\
M_{\mathrm{co}_{2}}=\gamma_{\mathrm{co}_{2}} M_{a h g, 1}
\end{gathered}
$$

where $\gamma_{\mathrm{Co}_{2}}$ is the conversion rate from NG burnt to $\mathrm{CO}_{2}$ emission. By utilizing AHG, HES_FTL is operated in a manner such that its APP is in full-production mode, with constant production rate $\left(M_{a p p}=45.3 \mathrm{kgs}^{-1}\right)$, water consumption rate $\left(M_{v_{-} a p p, 1}=232.49 \mathrm{kgs}^{-1}\right)$, and NG consumption rate $\left(M_{v_{-} a p p, 2}=52.6 \mathrm{kgs}^{-1}\right)$.

Fig. 5(a) shows the charge/discharge profile of standby battery for a period of 24 hours, where the largest single contiguous area represents the minimum storage capacity required. To determine the size of standby ESE, Monte Carlo approach is utilized as follows. Multiple year-long simulations are conducted, for each level of renewable prediction error, to numerically determine the minimum battery storage capacity required for that renewable prediction accuracy level. Fig. 5(b) shows the required storage size as a function of renewable prediction errors. Since in this paper the prediction error is assumed to be less than $30 \%$, an ESE with storage capacity of $15 \mathrm{MWh}$ is found to be sufficient for HES_FTL. Note that here the ESE capacity is chosen based on safety constraint only, i.e., sized to

\footnotetext{
${ }^{3}$ The values for $k_{0}$ and $k_{1}$ in (42) are determined by simulations of HES_FTL modeled in Modelica, and are given as $k_{0}=-8.07$ and $k_{1}=7.63 \times 10^{-2}$.
} 

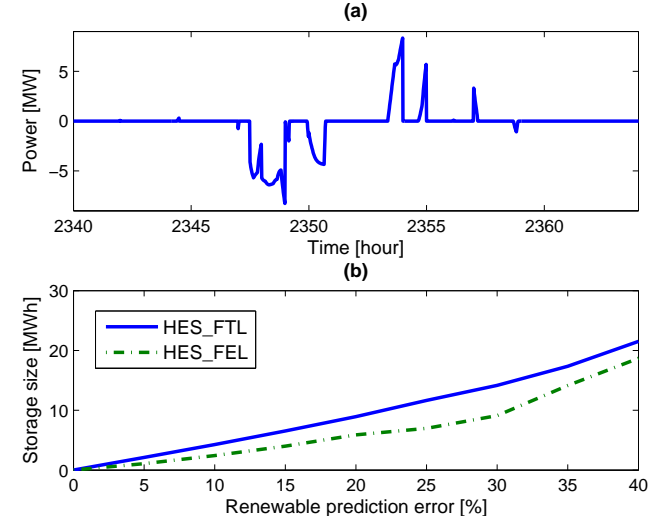

Figure 5: (a) Standby ESE charge (-) and discharge $(+)$ profile for a period of 24 hours; (b) Minimum ESE capacity required for different prediction errors.

cover prediction errors. This is because this paper focuses on operations optimization for a given and fixed system configuration, and so optimal sizing of ESE, as a design optimization problem, is beyond the scope of this paper.

\subsection{Hybrid Energy System with Flexible Electrical Load}

The second configuration, termed as HES_FEL (hybrid energy system with flexible electrical load), includes the following primary components:

- PHG, PC, and ESE: same as HES_FTL;

- REN: a PV solar station with nominal capability of up to $30 \mathrm{MW}$;

- AHG: none;

- APP: a reverse osmosis desalination plant (RODP) able to utilize up to $45 \mathrm{MW}$ electricity and convert saline or brackish water into fresh water and brine;

In this case, an RODP is used as APP, which requires electricity as its energy supplies. Since there is no AHG to supplement the energy supply to RODP, its production rate is varying between its minimum and maximum turndowns, i.e., between $P_{a p p}^{L}=15 \mathrm{MW}$ and $P_{a p p}^{U}=45$ MW. The variable O\&M cost of RODP is presented by a lump-sum variable cost, i.e., $N_{a p p}=1$, with $\beta_{v_{-} a p p, 1}$ being a lump-sum coefficient. For HES_FEL, the equality constraints (16) can be rewritten $\mathrm{as}^{4}$ :

$$
\begin{aligned}
M_{a p p} & =k_{0}+k_{1} P_{a p p}+k_{2} P_{a p p}^{2} \\
M_{\mathrm{co}_{2}} & =0 .
\end{aligned}
$$

Similarly, according to Fig. 5(b), a battery with storage capacity of $10 \mathrm{MWh}$ is found to be sufficient for HES_FEL.

\footnotetext{
${ }^{4}$ The values for $k_{0}, k_{1}$, and $k_{2}$ in $(43)$ are determined by simulations of HES_FEL modeling in Modelica, and are given as $k_{0}=$ $301.77, k_{1}=442.20$, and $k_{3}=-2.16$.
}

\subsection{Simulation setup}

The electricity and ancillary service prices in DAM, as well as the electricity price in RTM, both operated by Electric Reliability Council of Texas ${ }^{5}$, are used for $\pi_{d a, e}, \pi_{d a, a s}$ and $\pi_{r t}$, respectively, as shown in Fig. 6 for a selected period of 14 days. The wholesale price of $\mathrm{NG}^{6}$ and gasoline ${ }^{7}$ for a whole year are shown in Fig. 7(a). The price of water for HES_FEL, as shown in 7(b), is based on the monthly residential price in Phoenix, Arizona ${ }^{8}$, which is scaled so that the average of the time series is $\$ 0.6 / \mathrm{m}^{3}$ (the cost for purchasing groundwater or surface water in Arizona [49]).

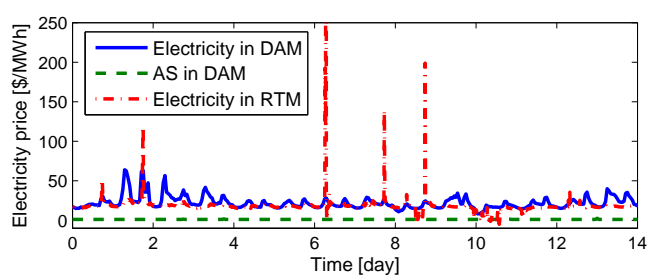

Figure 6: Prices for electricity and ancillary service for selected 14 days.
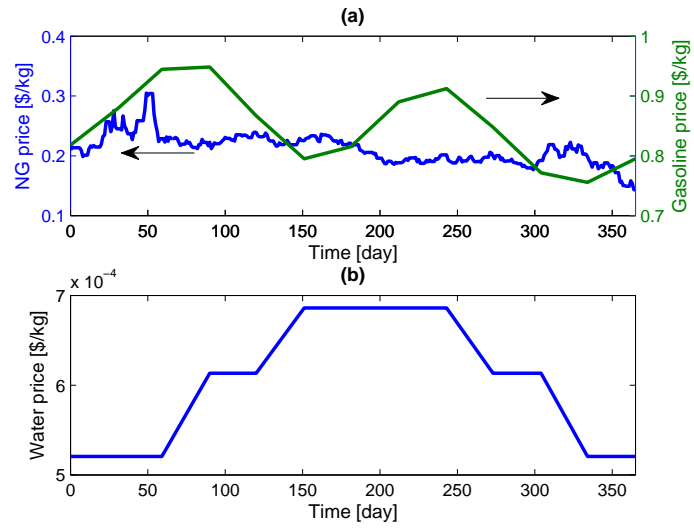

Figure 7: (a) Natural gas price and gasoline wholesale price for a whole year; (b) Water price for a whole year.

Renewable and price predictions. The predicted and actual renewable generation are synthesized based on reference time series, denoted as $r e f_{r}$, computed from real

\footnotetext{
${ }^{5}$ Downloaded from http://www.ercot.com/mktinfo/prices/ index.html on February 4, 2015. The time series is scaled by 0.75 to reflect the conservativeness of HES in bidding.

${ }^{6}$ The NG price is downloaded from Texas Alliance of Energy Producers at http://texasalliance.org/historical-nymex-natural-gasprices/ on February 4, 2015.

${ }^{7}$ The gasoline wholesale price by refinery is downloaded from EIA at http://www.eia.gov/dnav/pet/pet_pri_refmg_dcu_STX_m.htm on February 5, 2015.

${ }^{8}$ Downloaded from https://www.phoenix.gov/waterservices /customerservices/rateinfo on February 5, 2015.
} 
measurement data of wind speed ${ }^{9}$ and solar irradiation ${ }^{10}$. For a fixed prediction error $p_{r}$, the time series of predicted renewable generation for DAO, denoted as pred $_{r}$, is synthesized so that it is uniformly distributed within range $\left(1 \pm p_{r}\right)$ re $f_{r}$, while the time series of actual renewable generation, denoted as $a c t_{r}$, is synthesized so that, with probability of 0.9 , it is uniformly distributed within range $\left(1 \pm p_{r}\right) r e f_{r}$ and, with probability of 0.1 , it is uniformly distributed within range $\left(\left[1+p_{r}\right) r e f_{r},\left(1+2 p_{r}\right) r e f_{r}\right] \cup$ $\left[\left(1-2 p_{r}\right) r e f_{r},\left(1-p_{r}\right) r e f_{r}\right]$. The prediction of real-time electricity price for DAO is carried out in a similar fashion, which is synthesized based on reference price data (denoted as $r e f_{m}$ ) as shown in Fig. 6. For a fixed prediction error $p_{m}$, the time series of predicted real-time electricity price, denoted as pred $_{m}$, is synthesized so that it is uniformly distributed with range $\left(1 \pm p_{m}\right) r e f_{m}$. The time series of actual price $\left(a c t_{m}\right)$, is synthesized by $a c t_{m}=r e f_{m}$.

Simulation of ancillary service. According to [50], both California and New England deploy contingency reserves about twice per month, while it is about ten times more frequent for New York. The average deployment duration is around ten minutes. Therefore, we assume the probability that the sold ancillary service capacity will be called for is $0.3 \%$, i.e., $p_{a s}=0.003$, with deployment duration being 15 minutes.

All the simulations conducted are for a whole year period unless specified. Table $2 \& 3$ list all the parameter values for HES_FTL and HES_FEL, respectively.

\subsection{Optimization results with perfect prediction}

The optimal electrical production for HES_FTL for selected 14 days is shown in Fig. 8, assuming perfect prediction, where Fig. 8(a) shows the optimal electricity sold in DAM, ancillary service sold in DAM, and electricity sold in RTM, respectively, and Fig. 8(b) shows the total electricity delivered to the electric grid and net load ${ }^{11}$. Note the scenarios in which the committed ancillary service is called for are also simulated and included in Fig. 8(b). Considering the fact that PHG in this case can deliver a maximumpower of $180 \mathrm{MW}$, these results suggest that the operations optimizer tends to divert thermal power from PHG to GPP and sell this flexible electrical generation as ancillary service in DAM capacity market.

To illustrate the advantage of utilizing such an operations optimizer, a simulation with constant operations is conducted, in which the electricity sold in DAM is fixed at $171 \mathrm{MW}$. Without the presence of an operations optimizer, the ancillary service sold in DAM and electricity

\footnotetext{
${ }^{9}$ Downloaded from the Eastern Wind dataset maintained by NREL (National Renewable Energy Laboratory) at http://www.nrel.gov/electricity /transmission/eastern_wind_dataset.html on November 21, 2014.

${ }^{10}$ Downloaded from http://www.nrel.gov/midc/ssrp/ on November 21, 2014, provided by Southwest Solar Research Park dataset maintained by NREL (National Renewable Energy Laboratory).

${ }^{11}$ Net load: electrical generation delivered to the grid by PHG.
}

Table 2: Parameter values used for HES_FTL

\begin{tabular}{|c|c|c|c|c|}
\hline & & Value & Unit & Ref. \\
\hline $\begin{array}{l}\text { Nuclear \& } \\
\text { Power Cycle }\end{array}$ & $\begin{array}{l}\alpha_{p h g} \\
\beta_{f-p h g} \\
\mathcal{N}_{p h g}\end{array}$ & $\begin{array}{l}4718 \\
5.2 \\
180,000\end{array}$ & $\begin{array}{l}\$ \mathrm{~kW}^{-1} \\
\% \\
\mathrm{~kW}\end{array}$ & $\begin{array}{l}{[51,52]} \\
{[53]} \\
{[6]}\end{array}$ \\
\hline Wind Farms & $\begin{array}{l}\alpha_{\text {ren }} \\
\beta_{f \_r e n} \\
\mathcal{N}_{\text {ren }}\end{array}$ & $\begin{array}{l}2339.61 \\
1.6 \\
45,000\end{array}$ & $\begin{array}{l}\$ \mathrm{~kW}^{-1} \\
\% \\
\mathrm{~kW}\end{array}$ & $\begin{array}{l}{[54]} \\
{[54]} \\
{[6]}\end{array}$ \\
\hline Storage & $\begin{array}{l}\alpha_{\text {ese }} \\
\beta_{f \_ \text {ese }} \\
\mathcal{N}_{\text {ese }, 1} \\
\mathcal{N}_{\text {ese }, 2}\end{array}$ & $\begin{array}{l}81.42 \\
3 \\
16,000 \\
15,000\end{array}$ & $\begin{array}{l}\$ \mathrm{kWh}^{-1} \\
\% \\
\mathrm{kWh} \\
\mathrm{kWh}\end{array}$ & $\begin{array}{l}{[2]} \\
{[2]} \\
{[6]} \\
\text { Sec. } 6.1\end{array}$ \\
\hline $\mathrm{AHG}$ & $\begin{array}{l}\alpha_{a h g} \\
\beta_{f_{-} a h g} \\
\beta_{v_{-} a h g, 1} \\
\mathcal{N}_{a h g}\end{array}$ & $\begin{array}{l}1057.44 \\
3 \\
45,000\end{array}$ & $\begin{array}{l}\$ \mathrm{~kW}^{-1} \\
\% \\
\$ \mathrm{~kg}^{-1} \\
\mathrm{~kW}\end{array}$ & $\begin{array}{l}{[55]} \\
{[55]} \\
\text { Fig. } 7(\mathrm{a}) \\
{[6]}\end{array}$ \\
\hline $\begin{array}{l}\text { Gasoline } \\
\text { Production } \\
\text { Plant }\end{array}$ & $\begin{array}{l}\alpha_{a p p} \\
\beta_{f_{-} a p p} \\
\beta_{v_{-} g p p, 1} \\
\beta_{v_{-} g p p, 2} \\
\mathcal{N}_{a p p} \\
\pi_{a p p} \\
M_{v_{-} a p p, 1} \\
M_{v_{-} a p p, 2} \\
k_{0} \\
k_{1}\end{array}$ & $\begin{array}{l}42,661,291 \\
12 \\
1.059 \mathrm{e}^{-3} \\
45.3 \\
\\
232.49 \\
52.6 \\
-8.07 \\
7.63 \mathrm{e}^{-2}\end{array}$ & $\begin{array}{l}\$ \mathrm{~kg}^{-1} \mathrm{~s} \\
\% \\
\$ \mathrm{~kg}^{-1} \\
\$ \mathrm{~kg}^{-1} \\
\mathrm{kgs}^{-1} \\
\$ \mathrm{~kg}^{-1} \\
\mathrm{kgs}^{-1} \\
\mathrm{kgs}^{-1} \\
\mathrm{kgs}^{-1} \\
\mathrm{kgs}^{-1} \mathrm{MW}^{-1}\end{array}$ & $\begin{array}{l}56] \\
{[56]} \\
{[57]} \\
\text { Fig. } 7(\mathrm{a}) \\
{[6]} \\
\text { Fig. } 7(\mathrm{a}) \\
{[6]} \\
{[6]} \\
\text { footnote }^{3} \\
\text { footnote }^{3}\end{array}$ \\
\hline Electricity & $\begin{array}{l}\pi_{d a, e} \\
\pi_{d a, a s} \\
\pi_{r t} \\
p_{a s}\end{array}$ & 0.3 & $\begin{array}{l}\$ \mathrm{MWh}^{-1} \\
\$ \mathrm{MWh}^{-1} \\
\$ \mathrm{MWh}^{-1} \\
\%\end{array}$ & $\begin{array}{l}\text { Fig. } 6 \\
\text { Fig. } 6 \\
\text { Fig. } 6 \\
\text { [50] }\end{array}$ \\
\hline $\mathrm{CO}_{2}$ & $\begin{array}{l}\beta_{\mathrm{CO}_{2}} \\
\gamma_{\mathrm{CO}_{2}}\end{array}$ & $\begin{array}{l}0.045 \\
2.697867\end{array}$ & $\begin{array}{l}\$ \mathrm{~kg}^{-1} \\
1\end{array}$ & $\begin{array}{l}{[58]} \\
{[1]}\end{array}$ \\
\hline Inflation Rate & $i$ & 3 & $\%$ & Sec. 4 \\
\hline $\begin{array}{l}\text { Discount Rate } \\
\text { (WACC) }\end{array}$ & $r_{R}$ & 5 & $\%$ & Sec. 4 \\
\hline DA Rates & $\rho_{d a, k}$ & footnote $^{1}$ & $\%$ & {$[45]$} \\
\hline Tax Rate & $\sigma$ & 35 & $\%$ & {$[59]$} \\
\hline
\end{tabular}

sold in RTM are assumed to be 0 . Table 4 shows that the real discounted FCFF for the first year of operations increases from $\$ 421,434,281$ at constant operations mode to $\$ 433,151,990$ with the proposed operations optimizer (a $2.78 \%$ gain). The payback period is 8.13 years with operations optimizer while it is 8.43 years without, supporting the economic viability of HES_FTL. Moreover, the IRR is $14.7 \%$ for 30 years of operations with the proposed operations optimizer. The advantage of proposed operations optimizer is further illustrated by Fig. 9(a), which plots revised NPV as a function of operations time with and without the proposed operations optimizer, assuming that the market dynamics (e.g., price, production and consumption) in subsequent years are the same as those assumed for the first year. This revised NPV considers only the revenues and variable O\&M cost that are related to operations, including revenue from sale of electricity and ancillary service, and cost of consuming NG for AHG.

Similarly, Fig. 10 plots the optimal electrical production for HES_FEL for selected 14 days, assuming perfect prediction. A simulation with constant operations is also conducted, for which the electricity sold in DAM is fixed 
Table 3: Parameter values used for HES_FEL

\begin{tabular}{|c|c|c|c|c|}
\hline & & Value & Unit & Ref. \\
\hline $\begin{array}{l}\text { Nuclear \& } \\
\text { Power Cycle }\end{array}$ & $\begin{array}{l}\alpha_{p h g} \\
\beta_{f-p h g} \\
\mathcal{N}_{p h g}\end{array}$ & $\begin{array}{l}4718 \\
5.2 \\
180,000\end{array}$ & $\begin{array}{l}\$ \mathrm{~kW}^{-1} \\
\% \\
\mathrm{~kW}\end{array}$ & $\begin{array}{l}{[51,52]} \\
{[53]} \\
{[6]}\end{array}$ \\
\hline PV Station & $\begin{array}{l}\alpha_{\text {ren }} \\
\beta_{f-r e n} \\
\mathcal{N}_{\text {ren }}\end{array}$ & $\begin{array}{l}5385.98 \\
1 \\
30,000\end{array}$ & $\begin{array}{l}\$ \mathrm{~kW}^{-1} \\
\% \\
\mathrm{~kW}\end{array}$ & $\begin{array}{l}{[60]} \\
{[61]} \\
{[6]}\end{array}$ \\
\hline Storage & $\begin{array}{l}\alpha_{\text {ese }} \\
\beta_{f_{-} \text {ese }} \\
\mathcal{N}_{\text {ese }, 1} \\
\mathcal{N}_{\text {ese }, 2}\end{array}$ & $\begin{array}{l}81.42 \\
3 \\
52,700 \\
10,000\end{array}$ & $\begin{array}{l}\$ \mathrm{kWh}^{-1} \\
\% \\
\mathrm{kWh} \\
\mathrm{kWh}\end{array}$ & $\begin{array}{ll}{[2]} & \\
{[2]} & \\
{[6]} & \\
\text { Sec. } 6.2\end{array}$ \\
\hline $\begin{array}{l}\mathrm{RO} \\
\text { Desalination } \\
\text { Plant }\end{array}$ & $\begin{array}{l}\alpha_{a p p} \\
\beta_{f_{-} a p p} \\
\beta_{v_{-} a p p, 1} \\
\mathcal{N}_{a p p} \\
\pi_{a p p} \\
k_{0} \\
k_{1} \\
k_{2}\end{array}$ & $\begin{array}{l}32,076.21 \\
15 \\
6.6 \mathrm{e}^{-5} \\
15614 \\
\\
301.77 \\
442.20 \\
-2.16\end{array}$ & $\begin{array}{l}\$ \mathrm{~kg}^{-1} \mathrm{~s} \\
\% \\
\$ \mathrm{~kg}^{-1} \\
\mathrm{kgs}^{-1} \\
\$ \mathrm{~kg}^{-1} \\
\mathrm{kgs}^{-1} \\
\mathrm{kgs}^{-1} \mathrm{MW}^{-1} \\
\mathrm{kgs}^{-1} \mathrm{MW}^{-2}\end{array}$ & $\begin{array}{l}62] \\
{[62]} \\
{[63]} \\
{[6]} \\
\text { Fig. } 7(\mathrm{~b}) \\
\text { footnote } \\
\text { footnote } \\
\text { footnote }^{4}\end{array}$ \\
\hline Electricity & $\begin{array}{l}\pi_{d a, e} \\
\pi_{d a, a s} \\
\pi_{r t} \\
p_{a s}\end{array}$ & 0.3 & $\begin{array}{l}\$ \mathrm{MWh}^{-1} \\
\$ \mathrm{MWh}^{-1} \\
\$ \mathrm{MWh}^{-1} \\
\%\end{array}$ & $\begin{array}{l}\text { Fig. } 6 \\
\text { Fig. } 6 \\
\text { Fig. } 6 \\
{[50]}\end{array}$ \\
\hline Inflation Rate & $i$ & 3 & $\%$ & Sec. 4 \\
\hline $\begin{array}{l}\text { Discount Rate } \\
(\mathrm{WACC})\end{array}$ & $r_{R}$ & 5 & $\%$ & Sec. 4 \\
\hline DA Rates & $\rho_{d a, k}$ & footnote $^{1}$ & $\%$ & {$[45]$} \\
\hline Tax Rate & $\sigma$ & 40 & $\%$ & {$[59,64]$} \\
\hline
\end{tabular}

at $165 \mathrm{MW}$ while the ancillary service sold in DAM and electricity sold in RTM are assumed to be 0 . Table 5 shows that the real discounted FCFF increases from $\$ 77,278,730$ at constant operations mode to $\$ 140,938,245$ with the proposed operations optimizer (a $82.38 \%$ gain). Fig. 9(b) plots NPV as a function of operations time, indicating that payback period is about 15.29 years with the proposed operations optimizer. The IRR for 30 years of operations is $8.2 \%$ under the optimized case.

Remark 3. The revenue for HES_FTL consists a large portion (from sale of gasoline) that is constant with respect to operations, which limits the economic improvement brought by the proposed operations optimizer. On the other hand, all economic functions for HES_FEL de-

Table 4: Real discounted FCFF for 1st year of operations (HES_FTL).

\begin{tabular}{|l|l|l|l|}
\hline Economic value & $\begin{array}{l}\text { Optimal } \\
\text { operations }\end{array}$ & $\begin{array}{l}\text { Constant } \\
\text { operations }\end{array}$ & Gain \\
\hline Revenue - Electricity & $\$ 39,216,086$ & $\$ 43,200,065$ & $-9.22 \%$ \\
\hline Revenue - Gasoline & $\$ 1,218,737,232$ & $\$ 1,218,742,749$ & $0.00 \%$ \\
\hline Cost - CO2 & $(\$ 9,181,260)$ & $(\$ 15,893,894)$ & $-42.23 \%$ \\
\hline Cost - NG for AHG & $(\$ 16,005,811)$ & $(\$ 27,695,423)$ & $-42.21 \%$ \\
\hline Cost - NG for GPP & $(\$ 351,184,318)$ & $(\$ 351,184,318)$ & $0.00 \%$ \\
\hline Cost - Water & $(\$ 7,770,339)$ & $(\$ 7,770,339)$ & $0.00 \%$ \\
\hline FCFF & $\$ 433,151,990$ & $\$ 421,434,281$ & $2.78 \%$ \\
\hline
\end{tabular}
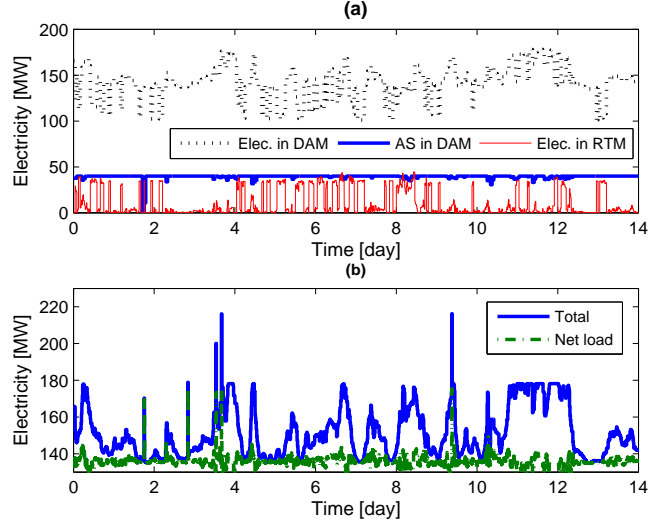

Figure 8: Optimization result for selected 14 days (HES_FTL) assuming perfect prediction: (a) Optimal electrical energy/capacity sold in each market; (b) Total electrical generation and net load.
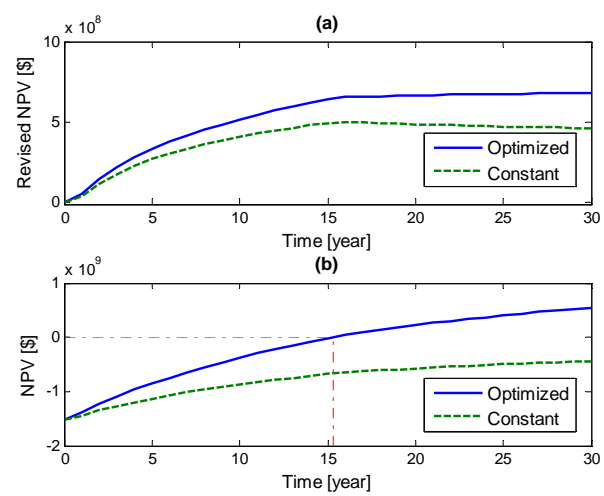

Figure 9: (a) Revised NPV as a function of operations time (HES_FTL) and (b) NPV as a function of operations time (HES_FEL), both assuming perfect prediction.

pend on operations. As illustrated by Fig. 9(b), without the proposed operations optimizer to accommodate the high variability and volatility in electricity, feedstock, and commodity market dynamics, HES_FEL is not economically attractive.

\subsection{Optimization results with imperfect prediction}

To illustrate the effect of prediction errors, Fig. 11 plots deviation of first year real discounted FCFF resulted by imperfect prediction $\left(\triangle F C F F_{R, 1}\right)$, for different levels of prediction errors for HES_FTL and HES_FEL respectively. In particular, $F C F F_{R, 1}$ monotonically decreases as renewable prediction error or real-time price prediction error increases, as expected.

\subsection{Sensitivity of market variations}

In order to measure the effect of market variations, Fig. 12 shows payback period as functions of price change and annual price growth rate, respectively, for HES_FTL, and 
(a)
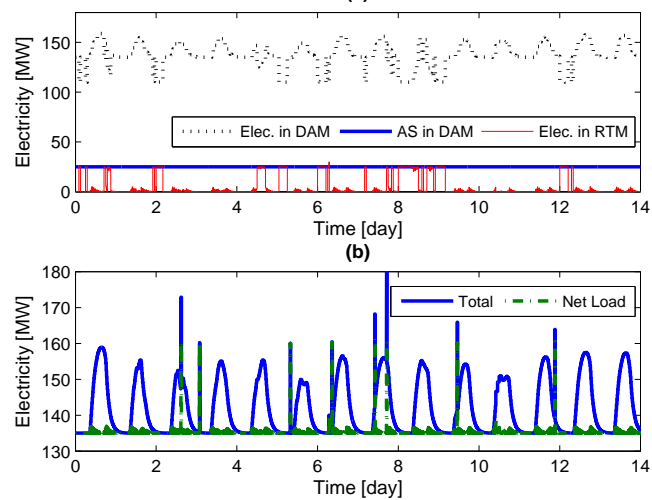

Figure 10: Optimization result for selected 14 days (HES_FEL) assuming perfect prediction: (a) Optimal electrical energy/capacity sold in each market; (b) Total electrical generation and net load.

Table 5: Real discounted FCFF for 1st year of operations (HES_FEL).

\begin{tabular}{|l|l|l|l|}
\hline Economic value & $\begin{array}{l}\text { Optimal } \\
\text { operation }\end{array}$ & $\begin{array}{l}\text { Constant } \\
\text { operation }\end{array}$ & Gain \\
\hline Revenue - Electricity & $\$ 38,256,342$ & $\$ 41,665,881$ & $-8.18 \%$ \\
\hline Revenue - Fresh water & $\$ 301,385,549$ & $\$ 178,461,804$ & $68.88 \%$ \\
\hline Cost - RODP & $(\$ 32,775,861)$ & $(\$ 19,360,846)$ & $69.29 \%$ \\
\hline FCFF & $\$ 140,938,245$ & $\$ 77,278,730$ & $82.38 \%$ \\
\hline
\end{tabular}

Fig. 13 shows IRR as a function of price change rate for HES_FEL. Constant operations mode is assumed for this analysis. These results suggest that the influence of electricity price on economic performance of HES is insignificant compared to those of feedstock and alternative commodity prices. In particular, HES_FTL may not be economically attractive if the price of gasoline decrease by $27 \%$ (or $4 \%$ every year), or NG price increases $8 \%$ every year.

\section{Conclusions and Ongoing Efforts}

This paper proposed a generic methodology for operations optimization for HES to maximize their economic performance based on predicted renewable generation and market information. To compensate for prediction error, a control strategy was accordingly designed to operate a standby energy storage element to avoid energy imbalance within HES. The proposed operations optimizer brings more opportunities for HES by enabling participation in various markets, including real-time market for nuclear generation and day-ahead market for renewable generation. The proposed operations optimizer was implemented in a multi-environment computational platform, and allows systematic control of energy conversion for maximal economic value. Simulation results of two specific HES
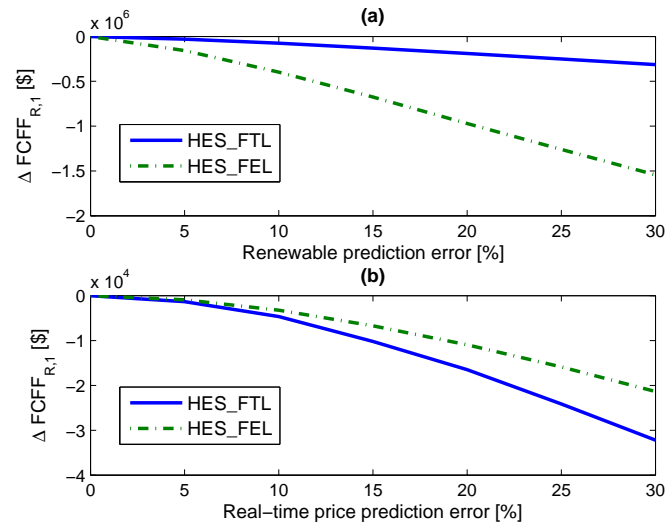

Figure 11: Deviation of first year FCFF as a function of prediction errors: (a) Renewable generation prediction error; (b) Real-time price prediction error.
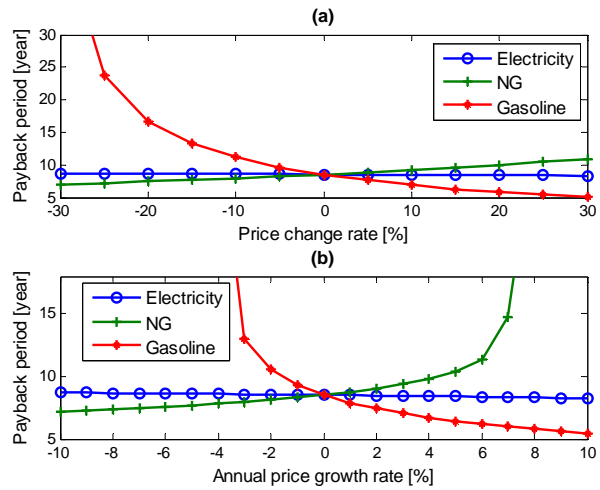

Figure 12: Sensitivity of payback period with respect to (a) price change and (b) annual price growth rate, assuming constant operations mode (HES_FTL).

configurations demonstrated the advantage of the proposed operations optimizer, and suggested operating HES by diverting energy for alternative energy output while participating in the ancillary service market. Sensitivity analysis with respect to market variation and prediction error were also performed to better understand the economic value of HES. Future efforts include model predictive control for operations to optimize combined technical and economic performance.

\section{Acknowledgment}

This research is supported by the Energy Security Initiative (ESI) and the Nuclear-Renewable Energy Systems Program at Idaho National Laboratory (INL) under the U.S. Department of Energy contract DE-AC-0705ID14517. The authors would like to acknowledge the assistance of Mr. Wesley R. Deason and Dr. Michael G. McKellar in providing part of cost parameters, and the leadership of Dr. Richard D. Boardman and Dr. Shannon 


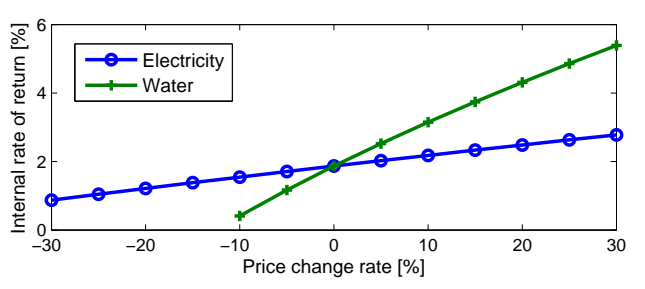

Figure 13: Sensitivity of IRR with respect to price change rate, assuming constant operations mode with perfect prediction (HES_FEL).

M. Bragg-Sitton in the Nuclear-Renewable Energy Systems Program at INL.

\section{Reference}

[1] H. E. Garcia, A. Mohanty, W. Lin, R. Cherry, Dynamic analysis of hybrid energy systems under flexible operation and variable renewable generation - part i: Dynamic performance analysis, Energy 52 (2013) 1-16.

[2] H. E. Garcia, A. Mohanty, W. Lin, R. Cherry, Dynamic analysis of hybrid energy systems under flexible operation and variable renewable generation - part ii: Dynamic cost analysis, Energy 52 (2013) $17-26$.

[3] W. R. Binder, C. J. Paredis, H. E. Garcia, Hybrid Energy System Modeling in Modelica, in: Proc. 10th Int. Modelica Conf., Lund, Sweden, 779-788, Mar. 10-12, 2014.

[4] W. Du, H. E. Garcia, C. J. J. Paredis, An Optimization Framework for Dynamic Hybrid Energy Systems, in: Proc. 10th Int. Modelica Conf., Lund, Sweden, 767-776, Mar. 10-12, 2014.

[5] H. E. Garcia, J. Chen, J. S. Kim, M. G. McKellar, W. R. Deason, R. B. Vilim, S. M. Bragg-Sitton, R. D. Boardman, Nuclear Hybrid Energy Systems - Regional Studies: West Texas \& Northeastern Arizona, Tech. Rep., Idaho Falls, ID: Idaho National Laboratory, INL/EXT-15-34503, Apr. 2015.

[6] H. E. Garcia, J. Chen, J. S. Kim, R. B. Villim, W. R. Binder, S. M. Bragg-Sitton, R. D. Boardman, M. G. McKellar, W. R. Deason, C. J. J. Paredis, Dynamic Performance Analysis of Two Regional Nuclear Hybrid Energy Systems, Energy (In press).

[7] J. S. Kim, J. Chen, H. E. Garcia, Modeling, control, and dynamic performance analysis of a reverse osmosis desalination plant integrated within hybrid energy systems, Energy (Submitted, under review).

[8] J. S. Kim, H. E. Garcia, Nuclear-Renewable Hybrid Energy System for Reverse Osmosis Desalination Process, in: Proc. 2015 Amer. Nucl. Soc. Annu. Meeting, vol. 112, San Antonio, TX, 121-124, Jun. 7-11, 2015.

[9] J. Chen, H. E. Garcia, J. S. Kim, S. M. Bragg-Sitton, Operations Optimization of Nuclear Hybrid Energy Systems, Nuclear Technology (In press).

[10] M. Tiller, Introduction to physical modeling with Modelica, Springer Science \& Business Media, 2001.

[11] D. Brück, H. Elmqvist, S. E. Mattsson, H. Olsson, Dymola for multi-engineering modeling and simulation, in: Proc. 2nd Int. Modelica Conf., Oberpfaffenhofen, Germany, Mar. 18-19, 2002.

[12] T. Blochwitz, M. Otter, M. Arnold, C. Bausch, C. Clauß, H. Elmqvist, A. Junghanns, J. Mauss, M. Monteiro, T. Neidhold, et al., The functional mockup interface for tool independent exchange of simulation models, in: Proc. 8th Int. Modelica Conf., Dresden, Germany, 105-114, Mar. 20-22, 2011.

[13] N. Fumo, P. J. Mago, L. M. Chamra, Emission operational strategy for combined cooling, heating, and power systems, Applied Energy 86 (11) (2009) 2344-2350.

[14] T. Nuytten, B. Claessens, K. Paredis, J. Van Bael, D. Six, Flexibility of a combined heat and power system with thermal energy storage for district heating, Applied Energy 104 (2013) 583-591.
[15] B. Rolfsman, Combined heat-and-power plants and district heating in a deregulated electricity market, Applied energy 78 (1) (2004) 37-52.

[16] H. Zhao, J. Holst, L. Arvastson, Optimal operation of coproduction with storage, Energy 23 (10) (1998) 859-866.

[17] J. L. Bernal-Agustín, R. Dufo-López, Simulation and optimization of stand-alone hybrid renewable energy systems, Renewable and Sustainable Energy Reviews 13 (8) (2009) 2111-2118.

[18] H. Ibrahim, R. Younès, T. Basbous, A. Ilinca, M. Dimitrova, Optimization of diesel engine performances for a hybrid winddiesel system with compressed air energy storage, Energy 36 (5) (2011) 3079-3091.

[19] M. Deshmukh, S. Deshmukh, Modeling of hybrid renewable energy systems, Renewable and Sustainable Energy Reviews 12 (1) (2008) 235-249.

[20] X. Wang, H. Teichgraeber, A. Palazoglu, N. H. El-Farra, An economic receding horizon optimization approach for energy management in the chlor-alkali process with hybrid renewable energy generation, J. Process Control 24 (8) (2014) 1318-1327.

[21] B. Zhu, H. Tazvinga, X. Xia, Switched model predictive control for energy dispatching of a photovoltaic-diesel-battery hybrid power system, IEEE Trans. Control Syst. Tech. 23 (3) (May 2015) 1229-1236.

[22] W. Chong, M. Naghavi, S. Poh, T. Mahlia, K. Pan, Technoeconomic analysis of a wind-solar hybrid renewable energy system with rainwater collection feature for urban high-rise application, Applied Energy 88 (11) (2011) 4067-4077.

[23] G. Graditi, M. G. Ippolito, E. Telaretti, G. Zizzo, An innovative conversion device to the grid interface of combined RES-based generators and electric storage systems, IEEE Transactions on Industrial Electronics 62 (4) (2015) 2540-2550.

[24] G. Bekele, B. Palm, Feasibility study for a standalone solarwind-based hybrid energy system for application in Ethiopia, Applied Energy 87 (2) (2010) 487-495.

[25] B. E. Türkay, A. Y. Telli, Economic analysis of standalone and grid connected hybrid energy systems, Renewable Energy 36 (7) (2011) 1931-1943.

[26] A. Fabbri, T. G. S. Román, J. R. Abbad, V. H. M. Quezada, Assessment of the cost associated with wind generation prediction errors in a liberalized electricity market, IEEE Transactions on Power Systems 20 (3) (2005) 1440-1446.

[27] G. Graditi, M. Ippolito, E. Telaretti, G. Zizzo, Technical and economical assessment of distributed electrochemical storages for load shifting applications: An Italian case study, Renewable and Sustainable Energy Reviews 57 (2016) 515-523.

[28] O. Ekren, B. Y. Ekren, Size optimization of a PV/wind hybrid energy conversion system with battery storage using simulated annealing, Applied Energy 87 (2) (2010) 592-598.

[29] B. Y. Ekren, O. Ekren, Simulation based size optimization of a PV/wind hybrid energy conversion system with battery storage under various load and auxiliary energy conditions, Applied Energy 86 (9) (2009) 1387-1394.

[30] O. Ekren, B. Y. Ekren, Size optimization of a PV/wind hybrid energy conversion system with battery storage using response surface methodology, Applied Energy 85 (11) (2008) 1086-1101.

[31] H. Yang, Z. Wei, L. Chengzhi, Optimal design and technoeconomic analysis of a hybrid solar-wind power generation system, Applied Energy 86 (2) (2009) 163-169.

[32] A. Kaabeche, M. Belhamel, R. Ibtiouen, Sizing optimization of grid-independent hybrid photovoltaic/wind power generation system, Energy 36 (2) (2011) 1214-1222.

[33] D. A. Hagos, A. Gebremedhin, B. Zethraeus, Towards a flexible energy system-A case study for Inland Norway, Applied Energy 130 (2014) 41-50.

[34] M. L. Di Silvestre, G. Graditi, E. R. Sanseverino, A generalized framework for optimal sizing of distributed energy resources in micro-grids using an indicator-based swarm approach, IEEE Transactions on Industrial Informatics 10 (1) (2014) 152-162.

[35] M. Di Somma, B. Yan, N. Bianco, G. Graditi, P. B. Luh, L. Mongibello, V. Naso, Operation optimization of a distributed energy system considering energy costs and exergy efficiency, Energy Conversion and Management 103 (2015) 739-751. 
[36] M. Ippolito, M. Di Silvestre, E. R. Sanseverino, G. Zizzo, G. Graditi, Multi-objective optimized management of electrical energy storage systems in an islanded network with renewable energy sources under different design scenarios, Energy 64 (2014) 648-662.

[37] G. Graditi, M. L. Di Silvestre, R. Gallea, E. Riva Sanseverino, Heuristic-based shiftable loads optimal management in smart micro-grids, IEEE Transactions on Industrial Informatics 11 (1) (2015) 271-280.

[38] R. Banos, F. Manzano-Agugliaro, F. Montoya, C. Gil, A. Alcayde, J. Gómez, Optimization methods applied to renewable and sustainable energy: A review, Renewable and Sustainable Energy Reviews 15 (4) (2011) 1753-1766.

[39] H. W. Kuhn, A. W. Tucker, Nonlinear Programing, in: 2nd Berkeley Symp. Math. Stat. Probability, Berkeley, USA, 481492, 1951.

[40] L. Zhi, J. Chen, P. Molnar, A. Behal, Weighted least-squares approach for identification of a reduced-order adaptive neuronal model, IEEE Trans. Neural Netw. Learning Syst. 23 (5) (2012) 834-840.

[41] J. Chen, J. Suarez, P. Molnar, A. Behal, Maximum likelihood parameter estimation in a stochastic resonate-and-fire neuronal model, in: Proc. 2011 IEEE Int. Conf. Computational Advances in Bio and Medical Sci. (ICCABS), Orlando, FL, 57-62, Feb. 3-5, 2011.

[42] N. Xue, W. Du, T. A. Greszler, W. Shyy, J. R. Martins, Design of a lithium-ion battery pack for PHEV using a hybrid optimization method, Appl. Energy 115 (2014) 591-602.

[43] R. H. Byrd, J. C. Gilbert, J. Nocedal, A trust region method based on interior point techniques for nonlinear programming, Math. Programming 89 (1) (2000) 149-185.

[44] C. Rabiti, R. S. Cherry, W. R. Deason, P. Sabharwall, S. M. Bragg-Sitton, R. D. Boardman, Framework for the Economic Analysis of Hybrid Systems Based on Exergy Consumption, Tech. Rep., Idaho Falls, ID: Idaho National Laboratory, INL/EXT-14-32934, Aug. 2014.

[45] Department of the Treasury, Internal Revenue Service, How to Depreciate Property, Publication 946. Cat. No. 13081F .

[46] P. W. Farris, N. T. Bendle, P. E. Pfeifer, D. J. Reibstein, Marketing metrics: The definitive guide to measuring marketing performance, Upper Saddle River, New Jersey: Pearson Education, Inc., 2010

[47] J. M. Moten Jr, C. Thron, Improvements on Secant Method for Estimating Internal Rate of Return (IRR), Int. J. Appl. Math. Stat. 42 (12) (2013) 84-93.

[48] D. Kirschen, G. Strbac, Fundamentals of Power System Economics, John Wiley \& Sond, Ltd, 2004.

[49] B. G. Colby, D. R. Smith, K. Pittenger, Enhancing supply reli- ability during drought, in: Arizona water policy: management innovations in an urbanizing, arid region, 2007.

[50] B. J. Kirby, Demand Response For Power System Reliability: FAQ, Tech. Rep., Oak Ridge, TN: Oak Ridge National Laboratory, ORNL/TM-2006/565, Dec. 2006.

[51] D. Shropshire, K. Williams, W. Boore, J. Smith, B. Dixon, M. Dunzik-Gougar, R. Adams, D. Gombert, E. Schneider, Advanced fuel cycle cost basis, Tech. Rep., Idaho Falls, ID: Idaho National Laboratory, INL/EXT-07-12107, 2007.

[52] Y. Du, J. E. Parsons, Update on the cost of nuclear power, MIT Center for Energy and Environmental Policy Research WP-2009-004.

[53] G. Rothwell, F. Ganda, Electricity Generating Portfolios with Small Modular Reactors, Tech. Rep., Lemont, IL: Argonne National Laboratory, 2014

[54] S. Tegen, M. Hand, B. Maples, E. Lantz, P. Schwabe, A. Smith, 2010 Cost of Wind Energy Review, Tech. Rep., Idaho Falls, ID: National Renewable Energy Laboratory, NREL/TP-500052920, Apr. 2012

[55] EIA, Updated capital cost estimates for electricity generation plants, Tech. Rep., Independent Statistics \& Analysis, U.S. Energy Information Administration, 2010.

[56] R. A. Wood, R. D. Boardman, M. W. Patterson, NuclearIntegrated Methanol-to-Gasoline Production Analysis, Tech. Rep., Idaho Falls, ID: Idaho National Laboratory, TEV-667, 2010 .

[57] City of Forth Worth, 2014 Water Rates, http:// fortworthtexas.gov/water/info/default.aspx?id=117022 .

[58] U.S. Department of Energy, Carbon capture technology program plan, Tech. Rep., U.S. Department of Energy, Jan. 2013.

[59] Department of the Treasury, Internal Revenue Service, Instruction for Form 1120: U.S. Corporation Income Tax Return .

[60] G. Barbose, N. Darghouth, S. Weaver, R. Wiser, Tracking the sun VI: An historical summary of the installed price of photovoltaics in the United States from 1998 to 2012, Tech. Rep., Lawrence Berkeley National Laboratory, LBNL-6350E, Sep. 2014.

[61] N. Enbar, PV O\&M Best Practices, Utility/Lab Workshop on PV Technology and Systems

62] IAEA, Economics of Nuclear Desalination: New Developments and Site Specific Studies, Tech. Rep., Int. Atomic Energy Agency, IAEA-TECDOC-1561, Jul. 2007.

[63] Yuma Area Office, United States Bureau of Reclamation, Yuma Desalting Plant Pilot Run Final Report, Tech. Rep., U.S Department of the Interior, Jul. 2012.

[64] Federation of Tax Administrators, Range of state corporate income tax rate, http://www.taxadmin.org/fta/default.html . 